NASA Contractor Report 189238

\title{
Effect of Inert Propellant Injection on Mars Ascent Vehicle Performance
}

James E. Colvin

University of Arizona Space

Engineering Research Center

Tucson, Arizona

and

Geoffrey A. Landis

Sverdrup Technology, Inc.

Lewis Research Center Group

Brook Park, Ohio

Prepared for the

28th Joint Propulsion Conference and Exhibit cosponsored by the AIAA, SAE, ASME, and ASEE

Nashville, Tennessee, July 6-8, 1992 


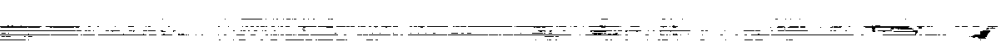

(1)

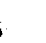

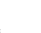

$=\ldots \ldots \ldots \ldots$

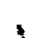

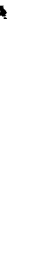

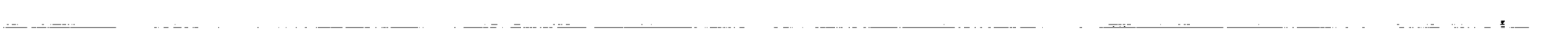




\title{
EFFECT OF INERT PROPELLANT INJECTION ON MARS ASCENT VEHICLE PERFORMANCE
}

\author{
James E. Colvin \\ University of Arizona Space \\ Engineering Research Center \\ Tucson, Arizona \\ and \\ Geoffrey A. Landis \\ Sverdrup Technology, Inc. \\ Lewis Research Center Group \\ Brook Park, Ohio
}

\begin{abstract}
A Mars ascent vehicle is limited in performance by the propellant which can be brought from Earth. In some cases the vehicle performance can be improved by injecting inert gas into the engine, if the inert gas is available as an in-situ resource and does not have to be brought from Earth. Carbon dioxide, nitrogen, and argon are constituents of the Martian atmosphere which could be separated by compressing the atmosphere, without any chemical processing step.

The effect of inert gas injection on rocket engine performance was analyzed with a numerical combustion code that calculated chemical equilibrium for engines of varying combustion chamber pressure, expansion ratio, oxidizer/fuel ratio, and inert injection fraction. Results of this analysis were applied to several candidate missions to determine how the required mass of return propellant needed in low Earth orbit could be decreased using inert propellant injection.
\end{abstract}




\section{NOMENCLATURE}

AR Area ratio of a nozzle

$\mathrm{CH}_{4}-\mathrm{O}_{2}$ methane/oxygen fueled engine

$\mathrm{CO}-\mathrm{O}_{2}$ carbon-monoxide/oxygen fueled engine

F thrust (nt)

g gravitational constant of Earth, $9.82 \mathrm{~m} / \mathrm{sec}$.

$\mathrm{H}_{2}-\mathrm{O}_{2}$ hydrogen/oxygen fueled engine

$\mathrm{I}_{\mathrm{sp}}$ (FO) fuel+oxidizer specific impulse (sec); thrust per unit fuel and oxidizer mass flow

$\mathrm{I}_{\mathrm{sp}}(\mathrm{P}) \quad$ propellant specific impulse (sec); thrust per unit propellant mass flow

$\mathrm{M}_{\mathrm{C}} \quad$ Earth return payload $(\mathrm{kg})$, including crew capsule, crew, suits, consumables, and soil samples.

$\mathrm{M}_{\mathrm{E}} \quad$ engine mass $(\mathrm{kg})$

$\dot{\mathrm{m}}_{\mathrm{F}+\mathrm{O}}$ mass flow of the energy-producing components of the propellant $(\mathrm{kg} / \mathrm{sec})($ fuel and oxidizer without the inert).

$\mathrm{M}_{\mathrm{f}} \quad$ burnout mass of stage $(\mathrm{kg})$

$\mathrm{M}_{\mathrm{i}} \quad$ initial mass of stage $(\mathrm{kg})$

$\mathrm{M}_{\mathrm{P}} \quad$ propellant mass $(\mathrm{kg})$

$\dot{\mathrm{m}}_{\text {total }}$ total mass flow of propellant $(\mathrm{kg} / \mathrm{sec})$

$\mathrm{M}_{\mathrm{T}} \quad$ tank and structure mass $(\mathrm{kg})$

$\mathrm{N}_{2} \quad$ nitrogen

O/F ratio of mass flow rate of oxidizer to mass flow rate of fuel into engine

$\Delta \mathrm{V} \quad$ velocity increment, $\mathrm{km} / \mathrm{sec}$ 


\section{INTRODUCTION}

It is possible for a return mission to the surface of Mars to be made significantly less costly if Mars derived resources can be used to provide some or all of the propellant required for the return to Earth. The mass of propellant that must be brought from low Earth orbit (LEO) to Mars for the return flight is significantly reduced by the use of local resources in propellant production ${ }^{1-5}$. The simplest resource available is the Martian atmosphere, which is present at every landing site and does not require prospecting or mining operations to acquire.

Most suggestions for utilization of the atmosphere of Mars involve gas separation and energy-intensive chemical processing into rocket fuel and oxidizer. However, it is worthwhile to consider uses of the Martian atmosphere which require no chemical processing.

One possible way to reduce the propellant mass brought from Earth would be to inject locally available "inert" gas into the propellant combustion flow of the return engines. (Here we use the word "inert" to designate a gas which adds mass to the exhaust but does not participate in chemical reactions with the propellant.) While this does not decrease fuel mass by as great a factor as chemical production of fuel or oxidizer, it has the advantage of being extremely simple: the process requires only compressing and liquefying the atmosphere.

Table I shows the composition of the Martian atmosphere. ${ }^{6}$ The most easily available choices for inert gas available from the Mars atmosphere are carbon dioxide, nitrogen, and argon.

\section{THEORY}

Rocket propellant can be conceptually divided into two elements: energy source and reaction mass. For some rocket types, such as a nuclear rocket, these are separate items. In a conventional chemical rocket, the energy source and the reaction mass are the same. However, it is also possible to add additional reaction mass to the exhaust. In this case the energy source is the chemical fuel and oxidizer, and the reaction mass is this plus the added inert component.

In the idealized case where the inert mass does not affect the combustion energy release, the thrust (and hence the total impulse) increases as the square root of the total mass flow: 


$$
F(\text { wih inet })=F(F+O \text { only }) \sqrt{\frac{\dot{m}_{\text {total }}}{\dot{m}_{F+O}}}
$$

Specific impulse $\left(\mathrm{I}_{\mathrm{sp}}\right)$ is the thrust per unit of mass flow. When inert reaction mass is added into the propellant, it is possible to define specific impulse two different ways. We will define the propellant specific impulse $I_{s p}(P)$ as the thrust per unit propellant mass flow, where the propellant includes both the energy producing components (fuel and oxidizer) plus the additional inert mass. The propellant specific impulse thus decreases as the square root of the total mass flow:

$$
\left.I_{s p}(P) \text { with inert injection }=I_{s p} \text { (no iner }\right) \sqrt{\frac{\dot{m}_{F+O}}{\dot{m}_{t o t a l}}}
$$

Here $I_{s p}$ (no inert) is the specific impulse of the fuel/oxidizer system without inert injection, $\dot{\mathrm{m}}_{\text {total }}$ is the total mass flow of propellant, and $\dot{\mathrm{m}}_{\mathrm{F}+\mathrm{O}}$ is the mass flow of the energy-producing components of the propellant (fuel and oxidizer without the inert).

Alternately, we define the fuel+oxidizer specific impulse $I_{s p}(F O)$ as the thrust per unit fuel and oxidizer mass flow, not including the additional inert mass. This is related to the propellant specific impulse by:

$$
I_{\text {sp }}(F+O)=I_{s p}(P)\left[\frac{\dot{m}_{\text {fuet }}+\dot{m}_{o x}+\dot{m}_{\text {inert }}}{\dot{m}_{o x}+\dot{m}_{\text {inert }}}\right]
$$

The fuel+oxidizer specific impulse increases as the inert flow increase. For a Mars-return vehicle where the fuel and oxidizer must be shipped from Earth, but inert gasses are locally available, the increase in fuel+oxidizer specific impulse may be more important than the decrease in propellant specific impulse.

For the case where the fuel and oxidizer are brought from Earth, it is desired to minimize the amount of fuel and oxidizer required per ton of payload delivered, or equivalently, to maximize the payload per unit amount of fuel and oxidizer. This is equivalent to optimizing the performance of a rocket where the energy source is fixed, but the specific impulse may be varied to maximize the payload. This can be calculated in closed form for the simple case where fixed mass such as tanks and engines are ignored ${ }^{7,8}$. If the (propellant) specific impulse is constant during thrust, the optimum is found when the specific impulse is proportional to the required mission delta-V: 


$$
\mathrm{gI}_{\mathrm{sp}}=0.625 \Delta \mathrm{V}
$$

For low mission $\Delta \mathrm{V}$, the increase in thrust outweighs the loss of propellant specific impulse, and adding inert reaction mass is effective. For high mission $\Delta \mathrm{V}$, the additional launch mass required by the lower specific impulse means that adding inert mass is not effective.

It is also worth noting that if the specific impulse is allowed to vary during the flight (for example, if the inert mass flow is allowed to vary), the optimum occurs when the exhaust velocity $\left[\mathrm{gI}_{\mathrm{sp}}(\mathrm{t})\right]$ is exactly equal to the mission velocity. This case was not examined in this study.

The present study addressed two questions:

(1) How does the addition of inert mass to the combustion chamber affect the thrust and specific impulse of rocket engines when real-world loses due to thermodynamics and chemical reaction are included in the analysis?

(2) Can the addition of inert reaction mass derived from the Martian atmosphere reduce the mission mass of a Mars return mission?

In addition to the possibility of increasing the amount of impulse produced by a fixed amount of fuel, it is also of interest to study inert injection for entirely Mars-derived fuel. There are two reasons for this. First, an actual operating plant to produce fuels from the Martian atmosphere will not produce fuels of $100 \%$ purity, and, in fact, it may add considerable mass and complexity to the system to remove the unnecessary ("inert") atmospheric components. Thus, it is of considerable interest to quantify how much degradation in performance results from residual inert composition of Mars-derived fuel or oxidizer. If, for example, an oxygen production plant still produces acceptable propellant if $50 \%$ nitrogen content remains in the fuel produced, the mass and complexity of the separation system may possibly be reduced.

The second reason is that propellant production on Mars is likely to be limited by the amount of energy available. Inert gas, on the other hand, will be produced by simple compression of the Martian atmosphere, a process requiring comparatively low energy consumption. Thus, like the case of Earth-derived fuels, it would be desirable to "stretch" the energy-intensive fuels with inert injection, if this is possible

To study inert injection using Mars resources, a two phase parametric study was 
undertaken. In phase I, the computer code Complex Chemical Equilibrium (CEC) ${ }^{9}$ was used to predict the effects on the vacuum specific impulse $\left(I_{\text {sp }}\right)$ by varying the percent of inert loading levels in the total propellant combustion flow-rate. This code calculates the equilibrium temperature, pressure, and chemical composition of the rocket combustion chamber and nozzle using known thermodynamic parameters of the propellant and exhaust products.

In phase II, the specific impulses calculated from CEC were used to examine the effect of inert propellant injection on several proposed mission scenarios. The desired conclusion from this study would be to show whether a mass savings from LEO could be realized by injecting inert propellant into the exhaust flow of the return engines.

\section{EFFECT OF INERT INJECTION ON ROCKET EFFICIENCY}

Three propellant combinations were studied. The hydrogen/oxygen $\left(\mathrm{H}_{2}-\mathrm{O}_{2}\right)$ fuel combination is typical of the highest specific impulse system available. Methane/oxygen $\left(\mathrm{CH}_{4}^{-}\right.$ $\mathrm{O}_{2}$ ) propellant has somewhat lower specific impulse, but the propellant is more compact, easier to store, and there is a possibility of manufacturing methane on Mars if hydrogen is brought from Earth ${ }^{3,4}$. Finally, the carbon monoxide/oxygen $\left(\mathrm{CO}-\mathrm{O}_{2}\right)$ propellant system might be manufactured using only Mars resources.

Likewise, the three most common inert gasses in the Martian atmosphere, carbon dioxide, nitrogen, and argon, were considered.

Using CEC, each propellant was examined by investigating the addition of one inert at a time and then by varying the inert loading level to $0,25,50,75,90$, and 95 percent of the total propellant mass flow-rate. The CEC code arbitrarily sets the total propellant mass flow-rate to be $1.0 \mathrm{~kg} / \mathrm{sec}$. The relative amounts of fuel and oxidizer is a variable. This is set as the mixture ratio $(\mathrm{O} / \mathrm{F})$ or the mass flow rate of oxidizer to the mass flow rate of fuel. The inert gas was, for convenience, assumed to be added in the same mass proportion to both the oxidizer and the fuel; this allows the combustion to have the same reaction stoichiometry independent of the inert injection. Practical engine design considerations will determine whether the inert is best added with the oxidizer, the fuel, or separately to the combustion chamber.

As an example calculation, consider the case of adding $25 \%$ inert to the baseline propellant $\mathrm{H}_{2}-\mathrm{O}_{2}$ with $\mathrm{O} / \mathrm{F}$ equaling 6.0. For the specified propellant mass flow-rate of $1 \mathrm{~kg} / \mathrm{sec}$, with no 
inert the $\mathrm{O}_{2}$ flow-rate is $0.857 \mathrm{~kg} / \mathrm{sec}$, and the $\mathrm{H}_{2}$ flow-rate $0.143 \mathrm{~kg} / \mathrm{sec}$. To add $25 \%$ inert requires $0.2143 \mathrm{~kg} / \mathrm{sec}$ of inert in the oxidizer and $0.0357 \mathrm{~kg} / \mathrm{sec}$ of inert in the hydrogen flow. The flowrates of the original propellant components must then be reduced by $25 \%$. Table II is a breakdown of the propellant flow-rate composition with the addition of $25 \%$ inert gas.

It can be seen from Table II that the total inert mass flow is $25 \%$ of the total, with the relative amounts of fuel and oxidizer still maintained at an $\mathrm{O} / \mathrm{F}$ of 6.0. Similar calculations were used for other inert loading levels. The results of these calculations provided input for CEC and were used to investigate the three propellant mixtures.

Combustion chamber pressures considered were 1.38 MPa (200 PSI), representative of a pressure-fed engine, and 20.7 MPa (3000 PSI), representative of a pump-fed engine. The nozzle exit area ratio (AR) was 200 . The engines were assumed to operate in vacuum, however, the atmospheric pressure on Mars is so low that there is negligible difference between operation in vacuum and on the Mars surface.

Figures 1-3 shows the change in propellant specific impulse with inert injection for hydrogen, methane, and carbon monoxide fueled engines. All of the inert gasses behave nearly the same, with a slightly worse performance from carbon dioxide injection compared to nitrogen or argon. The behavior follows almost exactly the ideal behavior (equation 2). For the remainder of the study, nitrogen was chosen to be the inert added. Since there was little difference in performance between inert gasses, similar results will apply for all.

Figure 4 shows the three fuels compared.

Figure 5 show the fuel+oxidizer $I_{\text {sp }}$ (as defined above) plotted as a function of the percentage of inert in the propellant mass flow, for the same conditions as figure 4 . As expected from equation 1 , the fuel+oxidizer specific impulse increases as inert propellant is added to the mixture.

O/F mixture ratios used for the previous figures were: 6.0 for $\mathrm{H}_{2}-\mathrm{O}_{2}, 3.4$ for $\mathrm{CH}_{4}-\mathrm{O}_{2}$, and 0.55 for $\mathrm{CO}-\mathrm{O}_{2}$ fueled engines. These mixture ratios are nearly optimal for performance with no inert injection.

Similar results were obtained for the chamber pressure of $20.7 \mathrm{MPa}$ (3000 PSI), shown in figures 6-11. Here we show the effect of the inert loading on $I_{s p}(P)$ and $I_{s p}(F+O)$ for various mixture ratios, keeping the AR constant at 200 . It is clear that the optimum mixture ratio does not depend on the inert injection. 
Finally, the effect of inert loading is shown for varying nozzle area ratio, again for 20.7 MPa chamber pressure and O/F close to stoichiometric. Figures 12 through 17 show the results of this analysis. The effectiveness of inert injection does not significantly depend on the area ratio.

\section{EFFECT OF INERT INJECTION ON MISSION MASS}

The data from Phase I show that as the inert loading level is increased, the propellant specific impulse decreases, but the fuel plus oxidizer specific impulse increases. The question of interest is, can the amount of $\mathrm{H}_{2}$ brought from LEO be reduced by the addition of locally available inerts in spite of the decreasing propellant specific impulse? To answer this question, two proposed mission scenarios were examined parametrically. The first was a two-stage direct launch from the surface to an Earth transfer orbit, following the mission parameters used in the "Mars Direct" mission proposed by Zubrin and Baker. ${ }^{3,4}$ The second scenario analyzed was a one-stage launch to Mars orbit for rendezvous with an orbiting Earth return vehicle ${ }^{10}$.

These two scenarios were chosen as representative of the range of values of Mars launch vehicle masses and their $\Delta V$ requirements for typical Mars return missions.

For the mission analyses, the inert used was nitrogen. Only the $\mathrm{H}_{2}-\mathrm{O}_{2}$ and $\mathrm{CH}_{4}-\mathrm{O}_{2}$ propellant combinations were considered, as the lower specific impulse of the carbon monoxide engine results in less advantage obtained from inert injection for the mission $\Delta \mathrm{Vs}$ considered. 


\section{"MARS DIRECT" MISSION}

\section{1: ENGINE:}

For the purpose of this study, it was assumed that the engine would be very similar to that of the Advanced Space Engine designed by Rocketdyne. Mass and thrust levels were modified slightly. The assumed mass per engine was $181 \mathrm{~kg}$. The assumed thrust per engine was fixed at $89 \mathrm{kN}$. In order to compare scenarios on the same basis, the thrust was assumed to be independent of the inert injection rate.

\section{2: SYSTEM MASS:}

The two stage mission described by Zubrin and Baker has an Earth return payload of $12,250 \mathrm{~kg}\left(\mathrm{M}_{\mathrm{C}}\right)$. It was assumed for this parametric study that the tank and structure mass $\left(M_{T}\right)$ would be $10 \%$ of the propellant mass per stage. The values of $M_{P}, M_{E}$, and $M_{T}$ were determined for each level of inert injection from the rocket equation (5). Only the first stage had the inert added to its propellant mix.

\section{3: SECOND STAGE:}

The calculation starts with the second (upper) stage, and then uses the second stage total mass as input to the calculation for the first (bottom) stage calculation. $\Delta V$ for the second stage burn was calculated from the quoted masses using the rocket equation:

$$
\Delta V=g I_{s p} \ln \left[\frac{M_{i}}{M_{f}}\right]
$$

where:

$$
\begin{aligned}
& M_{i}=M_{c}+M_{p}+M_{E}+M_{T} \\
& M_{F}=M_{i}-M_{p}
\end{aligned}
$$

Using Zubrin and Baker's mass values for the second stage $\left(\mathrm{M}_{\mathrm{P}}=22,170 \mathrm{~kg}\right.$ and $\mathrm{M}_{\mathrm{E}}=$ $2,560 \mathrm{~kg}$ ), a second-stage $\Delta V$ of $3,350 \mathrm{~m} / \mathrm{sec}$ was calculated.

Injection of inert mass into the second stage engine does not improve performance, and for these calculations the second stage was assumed to have zero inert injection. The mass breakdown is therefore only dependent upon the type of propellant used. A baseline case of $\mathrm{H}_{2}-\mathrm{O}_{2}$ was compared with the $\mathrm{CH}_{4}-\mathrm{O}_{2}$ propellant assumed by Zubrin and Baker. 
Table III shows the second-stage mass breakdown for $\mathrm{H}_{2}-\mathrm{O}_{2}$ propellant combination $\mathrm{I}_{\mathrm{sp}}=$ $495 \mathrm{sec}$.), and Table IV shows the mass breakdown using $\mathrm{CH}_{4}-\mathrm{O}_{2}$ propellant $\left(\mathrm{I}_{\mathrm{sp}}=384 \mathrm{sec}\right)$.

To verify that the assumed thrust levels and calculated masses are reasonable, the initial and final acceleration of the second stage burn were calculated, assuming the use of one $89 \mathrm{kN}$ engine. Accelerations are shown in Table $\mathrm{V}$ as a fraction of Earth and Mars gravitational acceleration. The values calculated are well within tolerable ranges for both hardware and crew safety.

For the $\mathrm{CH}_{4}-\mathrm{O}_{2}$ propellant, the $\mathrm{O} / \mathrm{F}$ ratio equals 3.4 , and thus $0.2273 \mathrm{~kg}$ of $\mathrm{CH}_{4}$ is needed per $\mathrm{kg}$ of propellant. The total amount of $\mathrm{CH}_{4}$ needed is $4,724 \mathrm{~kg}$. In the "Mars Direct" scenario, only the hydrogen is brought from Earth; methane is produced from it by a series of chemical processing steps. The relative masses of $\mathrm{C}$ and $\mathrm{H}$ in $\mathrm{CH}_{4}$ is $3: 1$, and so the mass of hydrogen that must be brought from LEO for use in the second stage is $1,181 \mathrm{~kg}$.

In the case of the $\mathrm{H}_{2}-\mathrm{O}_{2}$ propellant, the $\mathrm{O} / \mathrm{F}$ ratio equals 6.0 , resulting in the mass fraction of fuel in the propellant being $14.3 \%$. The total amount of hydrogen that must be brought from LEO is $1,960 \mathrm{~kg}$.

\section{FIRST STAGE ACCELERATIONS:}

A $\Delta V$ of $3,400 \mathrm{~m} / \mathrm{sec}$ was used for the first stage burn. Mass values for the first stage for the $\mathrm{CH}_{4}-\mathrm{O}_{2}$ case (no inert) are $\mathrm{M}_{\mathrm{P}}=70,160 \mathrm{~kg}$ and $\mathrm{M}_{\mathrm{E}}=8,850 \mathrm{~kg}$, plus the total second stage mass of $36,980 \mathrm{~kg}$.

Table VI and VII show the first stage mass breakdown for the $\mathrm{H}_{2}-\mathrm{O}_{2}$ and $\mathrm{CH}_{4}-\mathrm{O}_{2}$ case.

Again, acceleration was calculated to verify that the acceleration levels did not exceed reasonable limits. Consistent throughout these first stage calculations was the assumption of 15 engines with a total mass of $2,720 \mathrm{~kg}\left(\mathrm{M}_{E}\right)$. These engines combine for a total thrust of $1,330 \mathrm{kN}$. The thrust and engine masses were kept constant to keep the number of variables to a minimum in this analysis. (For an actual mission, thrust levels would be optimized with the number of engines being adjusted, and the engines throttled as necessary). Accelerations were calculated for two cases for each propellant mix: $0 \%$ inert addition and $75 \%$ inert addition.

Calculated accelerations are shown in Table VIII. The acceleration found is for all cases greater than one Mars gravity and within acceptable ranges. The purpose for using these two loading levels was to examine these values at two extremes. At an intermediate loading, the 
accelerations would be between these values.

\section{MASS OF HYDROGEN REQUIRED}

The mass of hydrogen brought from LEO for the first stage can now be calculated. We use the rocket equation, modified to account for tank and structure fraction (assumed to be $10 \%$ of propellant mass):

$$
M_{P}=\frac{(\xi-1)\left(M_{c}+M_{E}\right)}{1.1-0.1 \xi}
$$

where

$$
\xi=\frac{M_{i}}{M_{f}}=\exp \left[\frac{\Delta V}{g I_{s p}}\right]
$$

The mass of propellant necessary for the first stage engine can be calculated from these equations as a function of propellant specific impulse. To calculate the inert injection fraction which will give a specified propellant specific impulse, a fifth-order polynomial was fit to the calculated values of propellant specific impulse versus nitrogen addition shown in figure 4 . This was done using inert levels from $0 \%$ to approximately $90 \%$.

The mass of hydrogen in the first stage propellant mass was calculated by a similar procedure to that used for the second stage calculations, modified to account for the inert loading level. The total mass of hydrogen to be brought from LEO is then just the sum of the amounts needed for the first and second stages.

Figures 18 and 19 show the required amount of hydrogen to be brought from Earth, for hydrogen and methane fueled engines respectively, as a function of the amount of inert added. In both cases, the amount of hydrogen required decreases with inert injection, up to an optimum inert fraction of $60 \%$ to $70 \%$. This is consistent with the result estimated using equation (3), which predicts that the optimum propellant specific impulse for the $3400 \mathrm{~m} / \mathrm{sec}$ first stage $\Delta V$ is about 215 sec., well below the specific impulse of either the hydrogen or methane propellants without inert injection. The actual optimum is slightly higher, as expected, since equation (3) does not account for engine and tank mass.

The values shown are hydrogen mass only, assuming that the rest of the propellant is manufactured locally on Mars. If both fuel and oxidizer are brought from Earth, and only inert production is done on Mars, these masses are higher by a factor of 7 (for 
$\mathrm{H}_{2}-\mathrm{O}_{2}$ ) and 17.6 (for $\mathrm{CH}_{4}-\mathrm{O}_{2}$ ). The location and relative value of the minimum does not change.

\section{MISSION}

The "2015 Mission" scenario describes a single-stage launch to a return vehicle waiting in low Martian orbit (LMO) ${ }^{10}$. For the purpose of this study, it was assumed the engine mass was $600 \mathrm{~kg}$, with a thrust level of $133.5 \mathrm{kN}$ per engine. Three engines per mission were assumed. This results in a total engine mass of $1,800 \mathrm{~kg}$ and a total thrust of $400 \mathrm{kN}$. The payload mass is $5,400 \mathrm{~kg}$, and the $\Delta \mathrm{V}$ required is $5,320 \mathrm{~m} / \mathrm{s}$.

The propellant $\mathrm{I}_{\mathrm{sp}}$ predicted by CEC for this engine with no inert injection was 495 seconds for the $\mathrm{H}_{2}-\mathrm{O}_{2}$ propellant and 404 seconds for the $\mathrm{CH}_{4}-\mathrm{O}_{2}$ propellant. With the addition of $50 \%$ nitrogen, these values were reduced to $363 \mathrm{sec}$. and $306 \mathrm{sec}$. respectively. Using these values for propellant specific impulse and eqns. 5-7, mass breakdowns for these missions were calculated. This analysis was performed using the assumption that the tank fraction is $11 \%$ of the propellant mass. Table IX shows the mass breakdown for the two $\mathrm{H}_{2}$ $\mathrm{O}_{2}$ propellant missions, while Table $\mathrm{X}$ shows the mass breakdown for the two $\mathrm{CH}_{4}-\mathrm{O}_{2}$ propellant missions.

Again, accelerations were calculated for the beginning and end of the engine burn to insure the feasibility of the scenario in regards to crew and equipment safety. This was performed using the assumed total thrust level of $400 \mathrm{kN}$ with the derived system masses. The accelerations are shown in table XI.

The mass of hydrogen which must be brought from LEO for the hydrogen- and the methane- fueled " 2015 " mission scenarios were calculated by the same method used earlier.

Figures 20 and 21 show the amount of hydrogen which must be brought from LEO as a function of the percentage of inert loading level. For this mission, there is no advantage to inert injection.

This is slightly surprising, since the simple estimation using equation (3) suggests that the optimum $I_{\text {sp }}$ for this case should be about $340 \mathrm{sec}$. The difference shows that neglecting engine and tank mass is not result in an accurate estimate of whether inert injection will decrease the required hydrogen.

While there is no performance advantage of inert injection, the fact that inert addition has 
little effect on performance up to nearly $50 \%$ mass fraction of inert is itself a significant result. This indicates that high propellant purity is not a critical parameter in the design of manufacturing processes for Mars-manufactured propellant from a performance standpoint.

If the inert injection was done only at the beginning of the flight, when the required $I_{s p}$ is low, inert injection would have also resulted in a decreased hydrogen requirement for this mission as well. However, this would have required the assumption of a more complex engine than the one assumed. While there is no reason why such an engine could not be made, this engine type is not currently under study.

\section{CONCLUSIONS}

A novel Mars mission strategy was studied, where liquefied inert gasses from the Martian atmosphere are used as inert reaction mass to inject into the combustion chamber of an Earthreturn vehicle. This results in a greater mass of propellant used, but can result in a lower requirement for fuel brought from Earth. A standard rocket engine combustion code was run to analyze the effect of inert injection on engine performance.

Two missions and two propellant combinations were analyzed. For one case, a two-stage launch direct from the Mars surface to Earth, the inert injection was found to result in a reduced mass of fuel brought from Earth.

These missions were not designed to make optimum use of inert propellant injection, but were only representative cases of mission strategies currently being considered. The advantage of inert injection is greatest when inert injection is used on stages with low $\Delta v$; choosing the staging criterion carefully would clearly increase advantage. Design of new mission strategies specifically intended to take advantage of the increase in propellant leverage using inert gas injection may increase the amount gained by this strategy. For example, utilizing inert injection only during the beginning of the boost would allow the advantages of the injection but eliminate most of the penalty of higher propellant mass carried.

The mission analyses were all calculated using a fixed fraction of inert in each stage. It would be interesting to do the calculations assuming that the inert injection, and hence the I ${ }_{\text {sp' }}$ can be varied during the boost. This could result in additional mass savings. 


\section{REFERENCES}

1. French, J.R., "Rocket Propellants from Martian Resources," Journal of the British Interplanetary Society, Vol. 42, pp. 167-170, 1989.

2. Stancati, M.L., Niehoff, J.C., and Wells, W.C., "Mars Automated Refueling System Final Report and Presentation," Report No. SAI 1-120-196-S7, October, 1978.

3. Zubrin, R.M., and Baker, D. A., "Humans to Mars in 1999!," in Aerospace America, August, 1990.

4. Baker, D.A., and Zubrin, R.M., "Mars Direct," Journal of the British Interplanetary Soc., Vol. 42, No. 4, pp. 147-160, 1989.

5. Landis, G.A. and Linne, D.L., "Acetylene Fuel from Atmospheric $\mathrm{CO}_{2}$ on Mars," Journal of Spacecraft and Rockets,Vol. 29 No. 2, pp. 294-296, 1992.

6 Kaplan, D., "Environment of Mars, 1988," NASA Technical Memorandum 100470, October, 1988.

7. Leitman, G., "Propulsive Efficiency of Rockets," 3rd. International Symposium on Rockets and Astronautics, Tokyo, Japan, 1961; in expanded form in G. Leitman (ed.) Optimization Techniques, Chap. 13, pp. 377-388.

8. Zuppero, A., and Landis, G.A., "Optimum Rocket Propulsion for Energy-Limited Transfer," Ist. Annual Symposium on Resources of Near-Earth Space, 7-10 July, 1991, Tucson, AZ.

9. Gordon, S., and McBride, B.J., "Computer Program for Calculation of Complex Chemical Equilibrium Compositions, Rocket Performance, Incident and Reflected Shocks, and Chapman-Jouguet Detonations," NASA SP-273, March, 1976.

10. Donahue, B.; Boeing Co., "Orientation/1st Intern Briefing," NASA Contract NAS837857, December 1989. 
Table I.

Composition of the Martian Atmosphere (from ref. 6)

\begin{tabular}{|cc|}
\hline Gas & Percent (by mass) \\
\hline $\mathrm{CO}_{2}$ & 96.8 \\
$\mathrm{~N}_{2}$ & 1.7 \\
$\mathrm{Ar}$ & 1.4 \\
$\mathrm{O}_{2}$ & 0.1 \\
$\mathrm{CO}$ & 0.04 \\
$\mathrm{Ne}$ & $1.1 \mathrm{ppm}$ \\
$\mathrm{Kr}$ & $0.6 \mathrm{ppm}$ \\
$\mathrm{Xe}$ & $0.2 \mathrm{ppm}$ \\
\hline
\end{tabular}

Table II

Example Propellant Flow-rate

$0.2143 \mathrm{~kg} / \mathrm{sec}$ : inert in oxidizer

$0.0357 \mathrm{~kg} / \mathrm{sec}$ : inert in fuel

$0.6428 \mathrm{~kg} / \mathrm{sec}$ : oxidizer $\left(\mathrm{O}_{2}\right)$

$0.1072 \mathrm{~kg} / \mathrm{sec}$ : fuel $\left(\mathrm{H}_{2}\right)$

$1.0000 \mathrm{~kg} / \mathrm{sec}:$ Total Propellant

Table III

$\mathrm{H}_{2}-\mathrm{O}_{2}$ Second Stage Mass Breakdown

Propellant : $13,718 \mathrm{~kg}$

Tank: $\quad 1,372 \mathrm{~kg}$

Engine : $\quad 181 \mathrm{~kg}$

Capsule and payload: $\quad 12,250 \mathrm{~kg}$
Table IV

$\mathrm{CH}_{4}-\mathrm{O}_{2}$ Second Stage Mass Breakdown

Propellant : $20,784 \mathrm{~kg}$

Tank : $\quad 2,078 \mathrm{~kg}$

Engine : $\quad 181 \mathrm{~kg}$

Capsule and payload: $12,250 \mathrm{~kg}$

TOTAL : $35,294 \mathrm{~kg}$
Table V

Second Stage Accelerations

$$
\begin{array}{ccc}
\text { Propellant } & \begin{array}{c}
\text { Initial } \\
\text { Acceleration }
\end{array} & \begin{array}{c}
\text { Final } \\
\text { Acceleration }
\end{array} \\
\cline { 1 - 3 } \mathrm{H}_{2}-\mathrm{O}_{2} & 0.86 \mathrm{~g}_{\text {Mars }} & \begin{array}{c}
1.72 \mathrm{~g}_{\text {Mars }} \\
\end{array} \\
& 0.33 \mathrm{~g}_{\text {Earth }} & 0.66 \mathrm{~g}_{\text {Earth }} \\
& & \\
\mathrm{CH}_{4}-\mathrm{O}_{2} & 0.67 \mathrm{~g} \text { Mars } & 1.64 \mathrm{~g}_{\text {Mars }} \\
& 0.26 \mathrm{gEarh} & 0.63 \mathrm{gEarth}
\end{array}
$$

Table VI

$\mathrm{H}_{2}-\mathrm{O}_{2}$ First Stage Mass Breakdown

\begin{tabular}{lrr} 
& $0 \%$ Inert & $75 \%$ Inert \\
Propellant & $34,135 \mathrm{~kg}$ & $110,838 \mathrm{~kg}$ \\
Tank and & $3,413 \mathrm{~kg}$ & $11,084 \mathrm{~kg}$ \\
Structure & & \\
Engine & $2,722 \mathrm{~kg}$ & $2,722 \mathrm{~kg}$ \\
Payload & $27,521 \mathrm{~kg}$ & $27,521 \mathrm{~kg}$ \\
\hline TOTAL & $67,791 \mathrm{~kg}$ & $152,164 \mathrm{~kg}$ \\
I & $15 \mathrm{sp}=495 \mathrm{sec}$ (no iner); $266 \mathrm{sec}$ (75\% inert).
\end{tabular}


Table VII

$\mathrm{CH}_{4}-\mathrm{O}_{2}$ First Stage Mass Breakdown

$(\Delta \mathrm{V}=3,400 \mathrm{~m} / \mathrm{s})$

$0 \%$ Inert $75 \%$ Inert

Propellant $\quad 56,572 \mathrm{~kg} \quad 196,900 \mathrm{~kg}$

Tank and $\quad 5,637 \mathrm{~kg} \quad 1,969 \mathrm{~kg}$

Structure

Engine

$2,722 \mathrm{~kg} \quad 2,722 \mathrm{~kg}$

Payload

$33,348 \mathrm{~kg} \quad 33,348 \mathrm{~kg}$

TOTAL

$98,279 \mathrm{~kg} \quad 252,660 \mathrm{~kg}$

$I_{S p}=404 \sec$ (no inert); $229 \sec$ (75\% inert)

Table VIII

First Stage Accelerations $(\Delta V=3,400 \mathrm{~m} / \mathrm{s})$

\begin{tabular}{|c|c|c|c|}
\hline & $\mathrm{m} / \mathrm{s}^{2}$ & $\mathrm{~g}_{\text {Mars }}$ & gEarth \\
\hline$\overline{\mathrm{H}_{2}-\mathrm{O}_{2}}$ & \multicolumn{3}{|c|}{ with 0\% Inert } \\
\hline A (initial) & 19.68 & 5.26 & 2.01 \\
\hline A (final) & 39.65 & 10.60 & 4.04 \\
\hline \multicolumn{4}{|c|}{ with $75 \%$ Inert } \\
\hline A (initial) & 8.77 & 2.34 & 0.89 \\
\hline A (final) & 32.29 & 8.63 & 3.29 \\
\hline
\end{tabular}

\begin{tabular}{|llll|}
\hline $\mathrm{CH}_{4}-\mathrm{O}_{2}$ & \multicolumn{4}{l|}{ with 0\% } & Inert \\
$\mathrm{A}$ (initial) & 13.58 & 3.63 & 1.38 \\
$\mathrm{~A}$ (final) & 31.98 & 8.55 & 3.26 \\
& & & \\
& \multicolumn{4}{c}{ with $75 \%$} & Inert & \\
A (initial) & 5.28 & 1.41 & 0.54 \\
A (final) & 23.93 & 6.40 & 2.44 \\
\hline
\end{tabular}

\section{Table IX}

$\mathrm{H}_{2}-\mathrm{O}_{2}$ Propellant Mission Mass Breakdown (single stage to Mars orbit)

\begin{tabular}{lrr} 
& 0\% Inert & 50\% Inert \\
Propellant & $18,405 \mathrm{~kg}$ & $40,430 \mathrm{~kg}$ \\
Tank and & $2,024 \mathrm{~kg}$ & $4,447 \mathrm{~kg}$ \\
Structure & & \\
Engine & $1,800 \mathrm{~kg}$ & $1,800 \mathrm{~kg}$ \\
Payload & $5,406 \mathrm{~kg}$ & $5,406 \mathrm{~kg}$ \\
\hline TOTAL & $27,635 \mathrm{~kg}$ & $52,083 \mathrm{~kg}$
\end{tabular}

\section{Table $\mathrm{X}$}

$\mathrm{CH}_{4}-\mathrm{O}_{2}$ Propellant Mission Mass Breakdown (single stage to Mars orbit)

\begin{tabular}{lrr} 
& $0 \%$ Inert & $50 \%$ Inert \\
Propellant & $29,553 \mathrm{~kg}$ & $76,603 \mathrm{~kg}$ \\
Tank and & $3,251 \mathrm{~kg}$ & $8,426 \mathrm{~kg}$ \\
Structure & & \\
Engine & $1,800 \mathrm{~kg}$ & $1,800 \mathrm{~kg}$ \\
Payload & $5,406 \mathrm{~kg}$ & $5,406 \mathrm{~kg}$ \\
\hline TOTAL & $40,010 \mathrm{~kg}$ & $92,236 \mathrm{~kg}$
\end{tabular}




\section{Table XI}

2015 Mission Accelerations

\begin{tabular}{|c|c|c|c|}
\hline & $\mathrm{m} / \mathrm{s}^{2}$ & gMars & gEarth \\
\hline \multicolumn{4}{|c|}{$\mathrm{H}_{2}-\mathrm{O}_{2}$ with 0\% Inert } \\
\hline A (initial) & 14.49 & 3.87 & 1.48 \\
\hline A (final) & 43.37 & 11.60 & 4.42 \\
\hline \multicolumn{4}{|c|}{ with 50\% Inert } \\
\hline A (initial) & 7.69 & 2.06 & 0.78 \\
\hline$A$ (final) & 34.35 & 9.19 & 3.50 \\
\hline
\end{tabular}

\begin{tabular}{|llrr|}
\hline $\mathrm{CH}_{4}-\mathrm{O}_{2}$ & \multicolumn{4}{l|}{ with 0\% } & Inert \\
$\mathrm{A}$ (initial) & 10.01 & 2.68 & 1.02 \\
$\mathrm{~A}$ (final) & 38.28 & 10.24 & 3.90 \\
& & & \\
& \multicolumn{4}{c}{ with 50\% Inert } \\
A (initial) & 4.34 & 1.16 & 0.44 \\
$\mathrm{~A}$ (final) & 25.61 & 6.85 & 2.61 \\
\hline
\end{tabular}




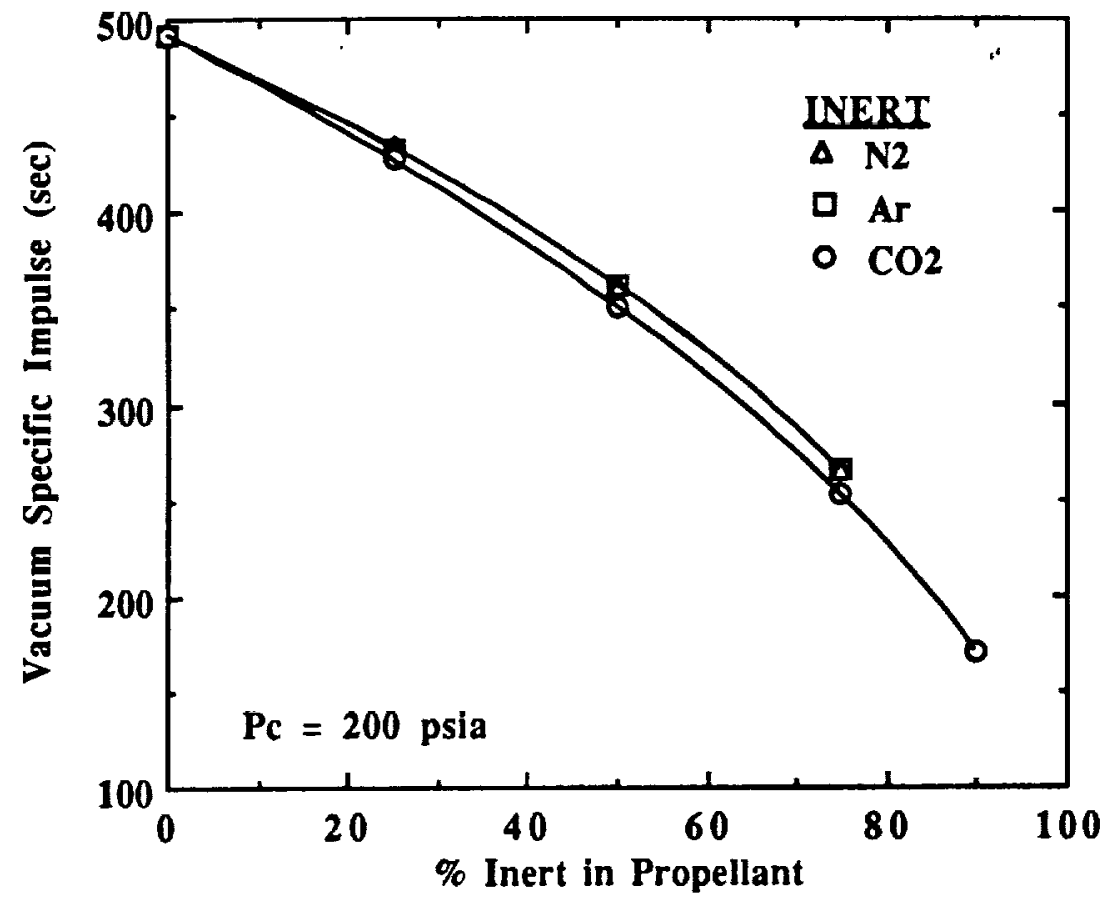

Figure 1. Effect on propellant specific impulse of addition of inert reaction mass to $\mathrm{H}_{2}-\mathrm{O}_{2}$ fueled engine

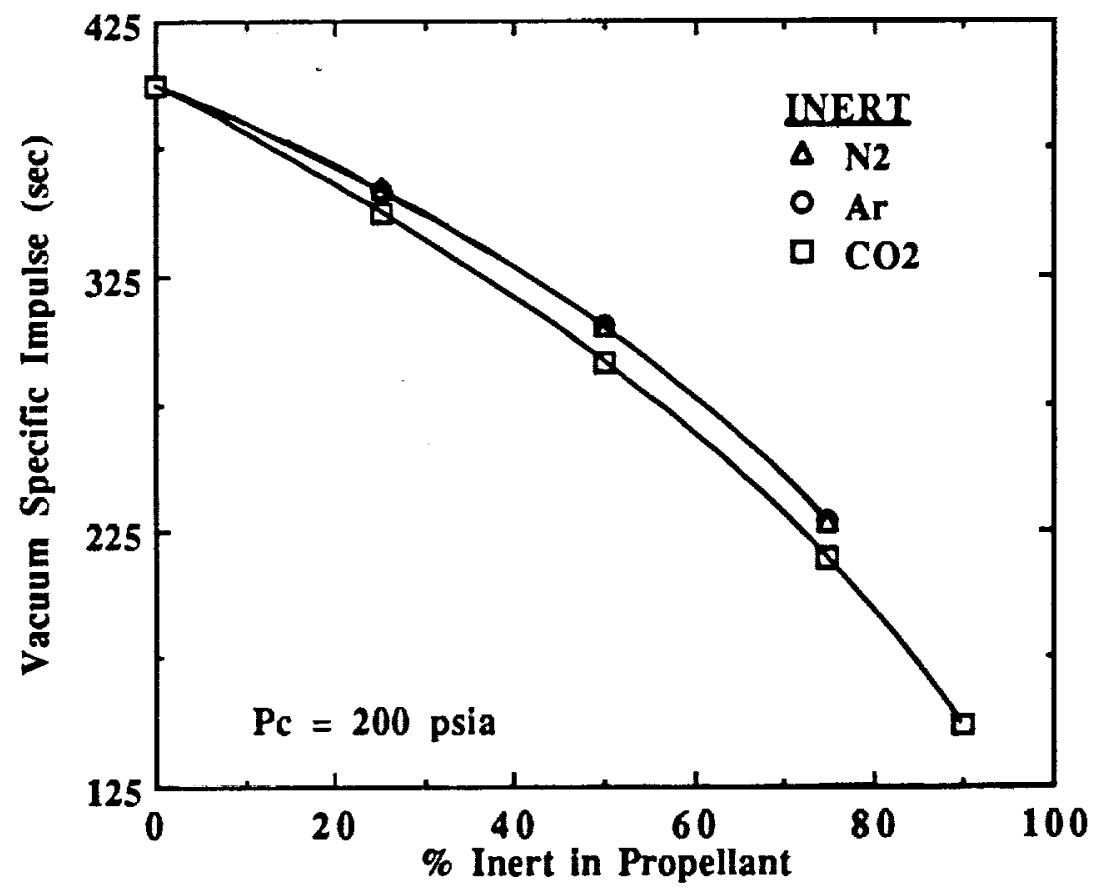

Figure 2. Effect on propellant specific impulse of addition of inert reaction mass to $\mathrm{CH}_{4}-\mathrm{O}_{2}$ fueled engine 


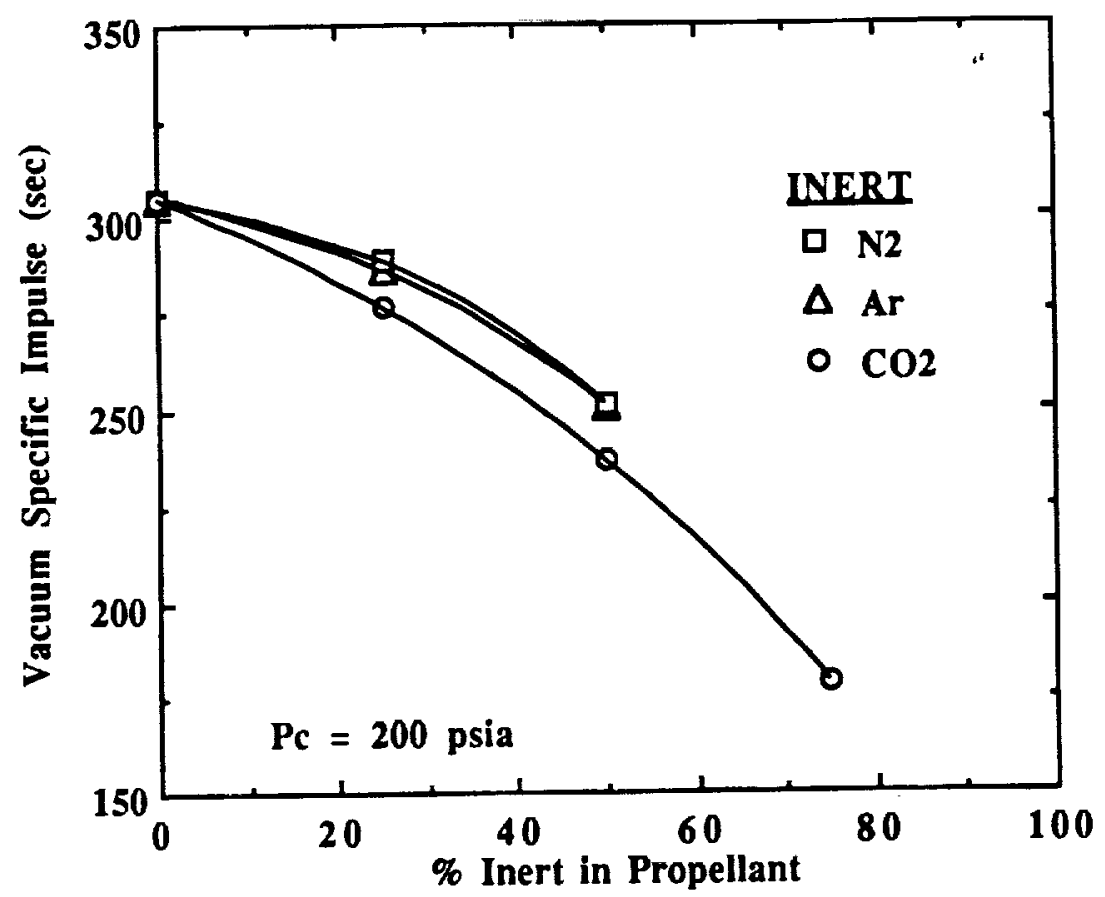

Figure 3. Effect on propellant specific impulse of addition of inert reaction mass to $\mathrm{CO}-\mathrm{O}_{2}$ fueled engine

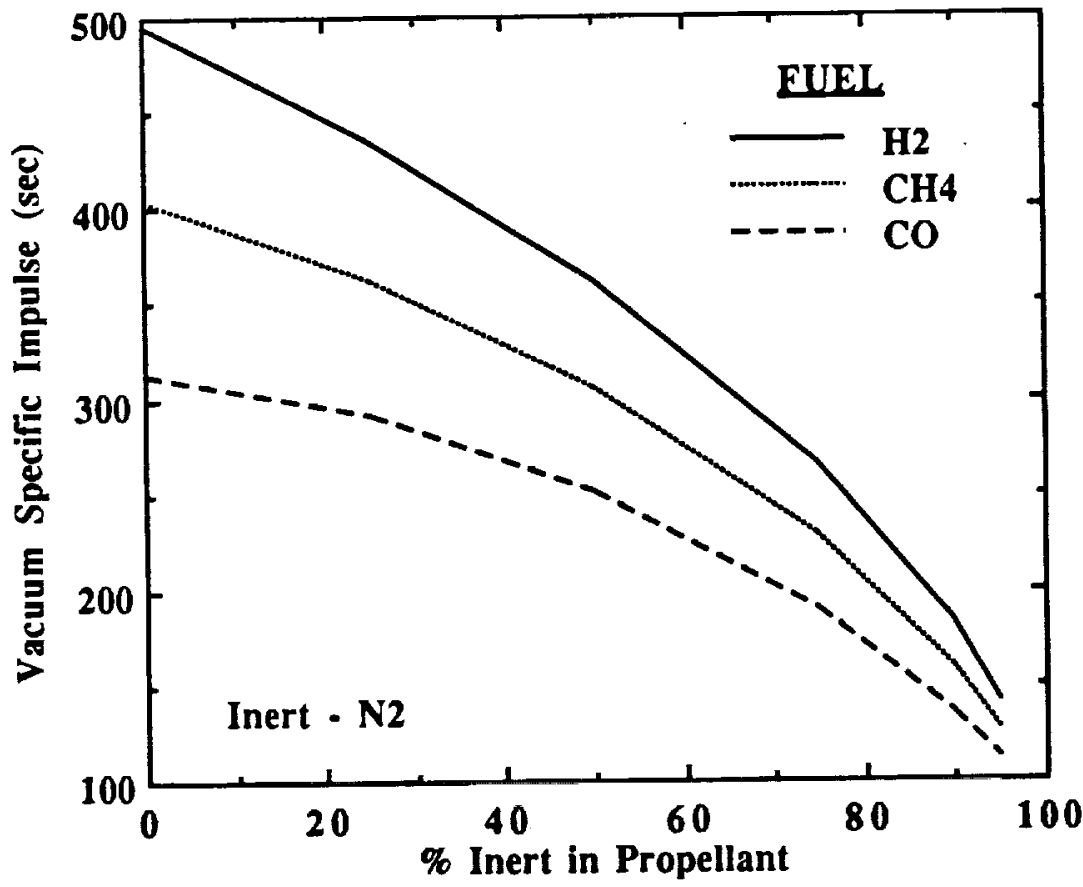

Figure 4. Comparison of effect on propellant specific impulse due to the addition of local inert to hydrogn, methane, and carbon monoxide fueled engines 


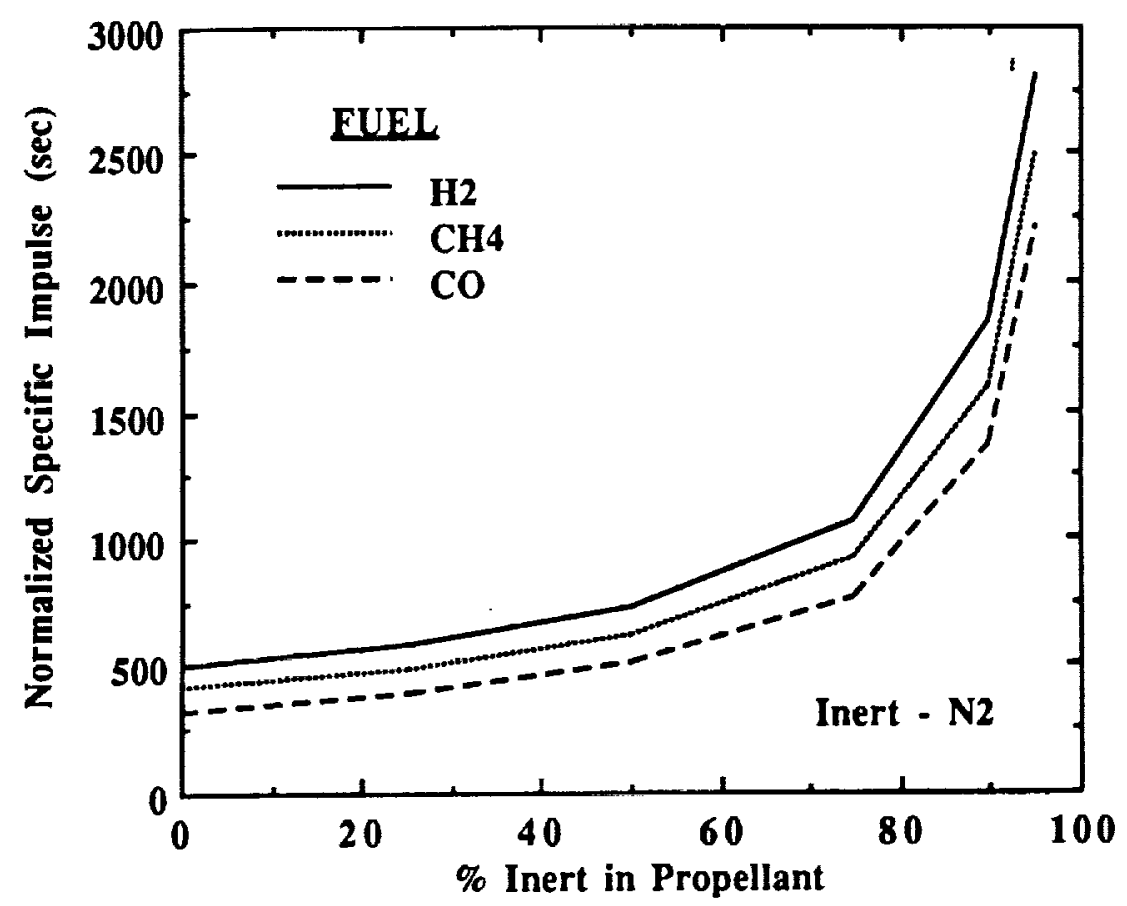

Figure 5. Isp $(F+O)$ [Specific impulse normalized to fuel and oxidizer flow], showing effect of addition of inert reaction mass to hydrogen, methane, and carbon monoxide fueled engines

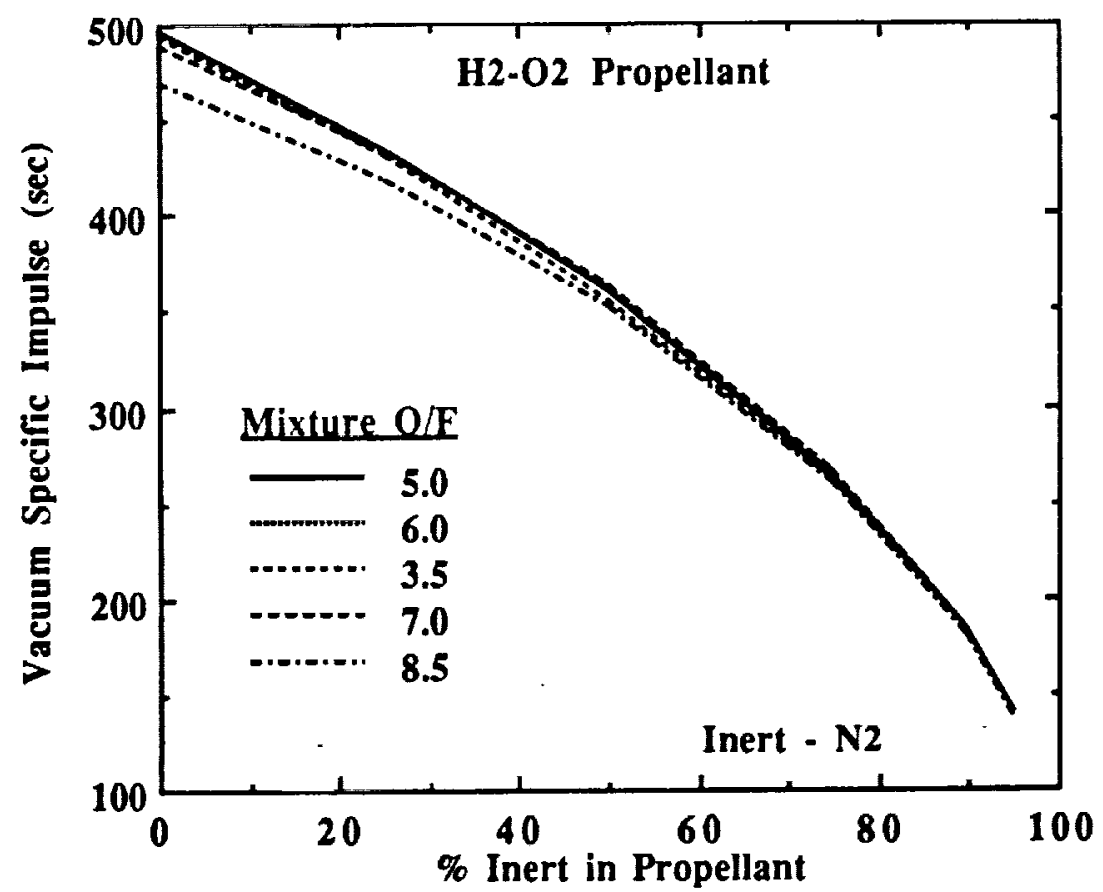

Figure 6. The effects on propellant specific impulse of addition of $\mathrm{N}_{2}$ to $\mathrm{H}_{2}-\mathrm{O}_{2}$ fueled engine while varying the $\mathrm{O} / \mathrm{F}$ mixture ratio

(Exit Area Ratio Constant at 200) 


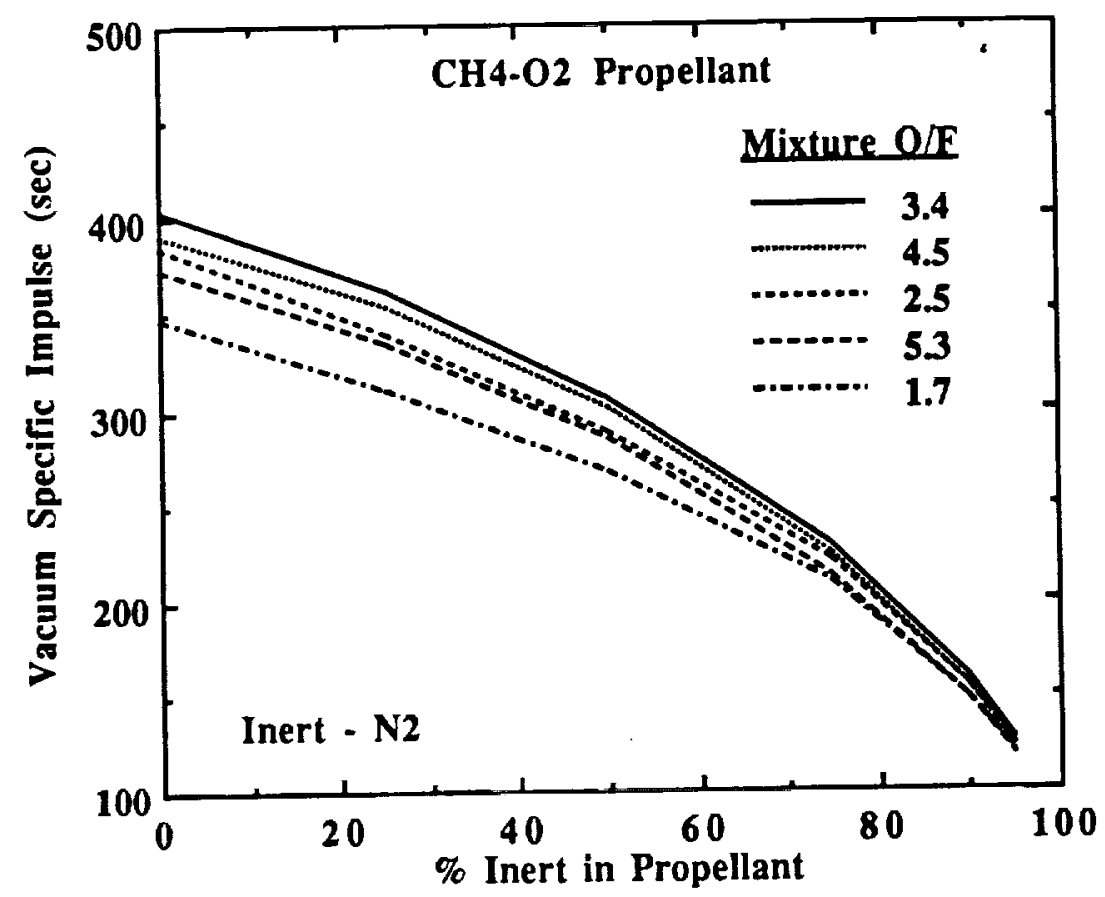

Figure 7. The Effects on propellant specific impulse of addition of $\mathrm{N}_{2}$ to $\mathrm{CH}_{4}-\mathrm{O}_{2}$ fueled engine while varying the $\mathrm{O} / \mathrm{F}$ mixture ratio ( Exit Area Ratio Constant at 200)

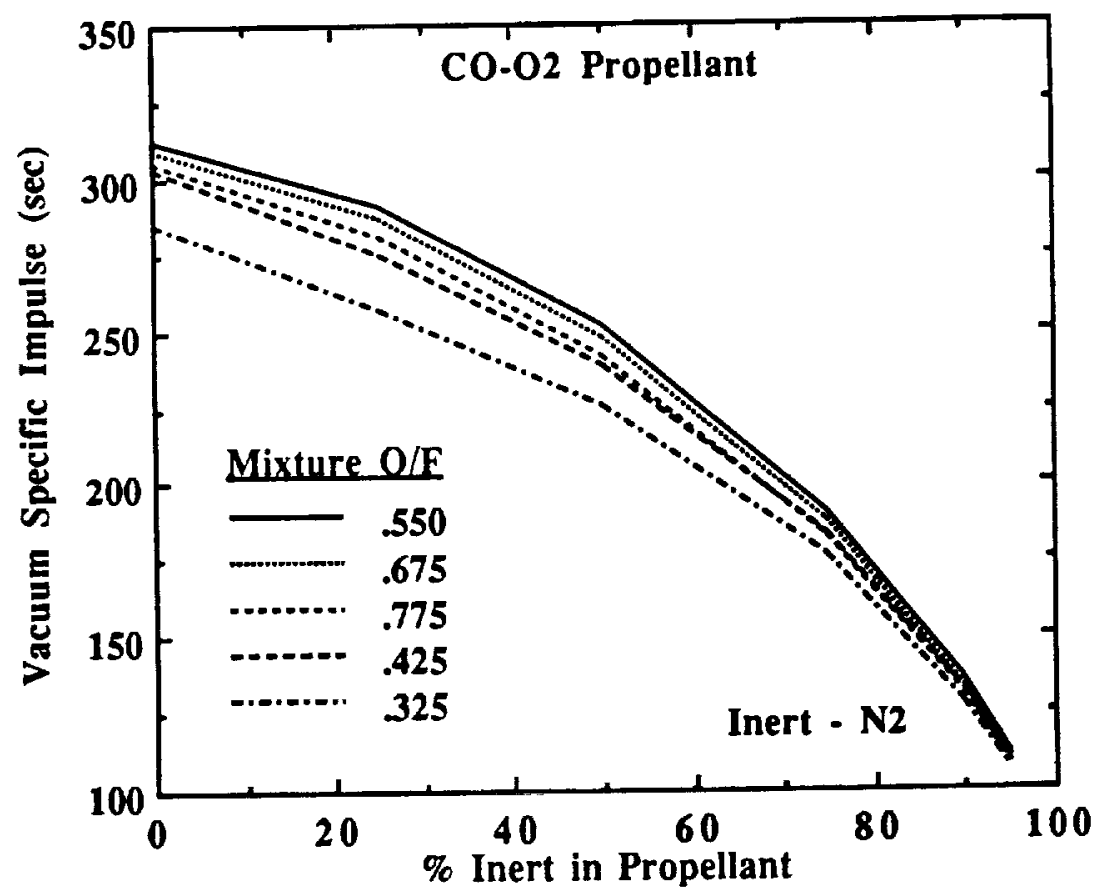

Figure 8. The effect on propellant specific impulse of addition of $\mathrm{N}_{2}$ to $\mathrm{CO}-\mathrm{O}_{2}$ fueled engine while varying the $\mathrm{O} / \mathrm{F}$ mixture ratio

(Exit Area Ratio Constant at 200) 


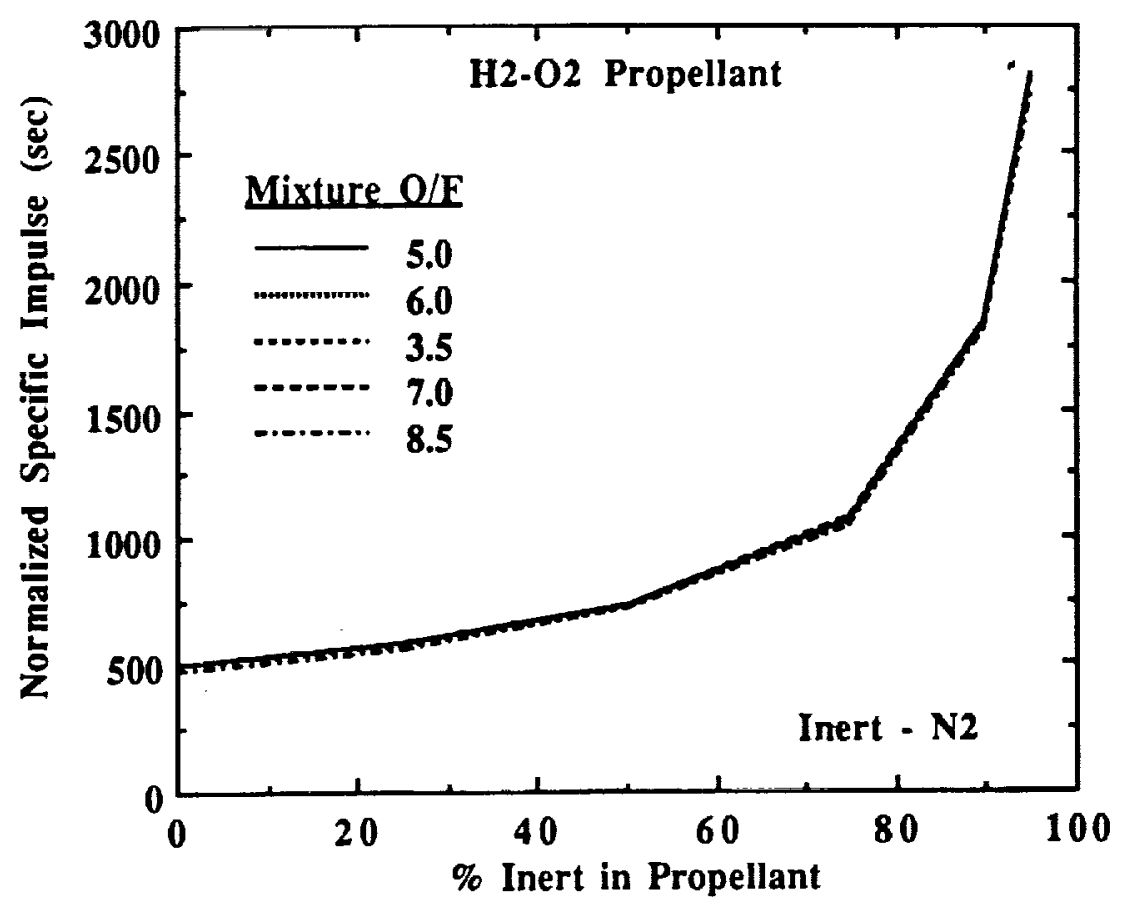

Figure 9. Isp $(F+O)$ [Specific impulse normalized to fuel and oxidizer flow], showing effect of addition of inert reaction mass to hydrogen fueled engine while varying the mixture ratio (Exit Area Ratio Constant at 200)

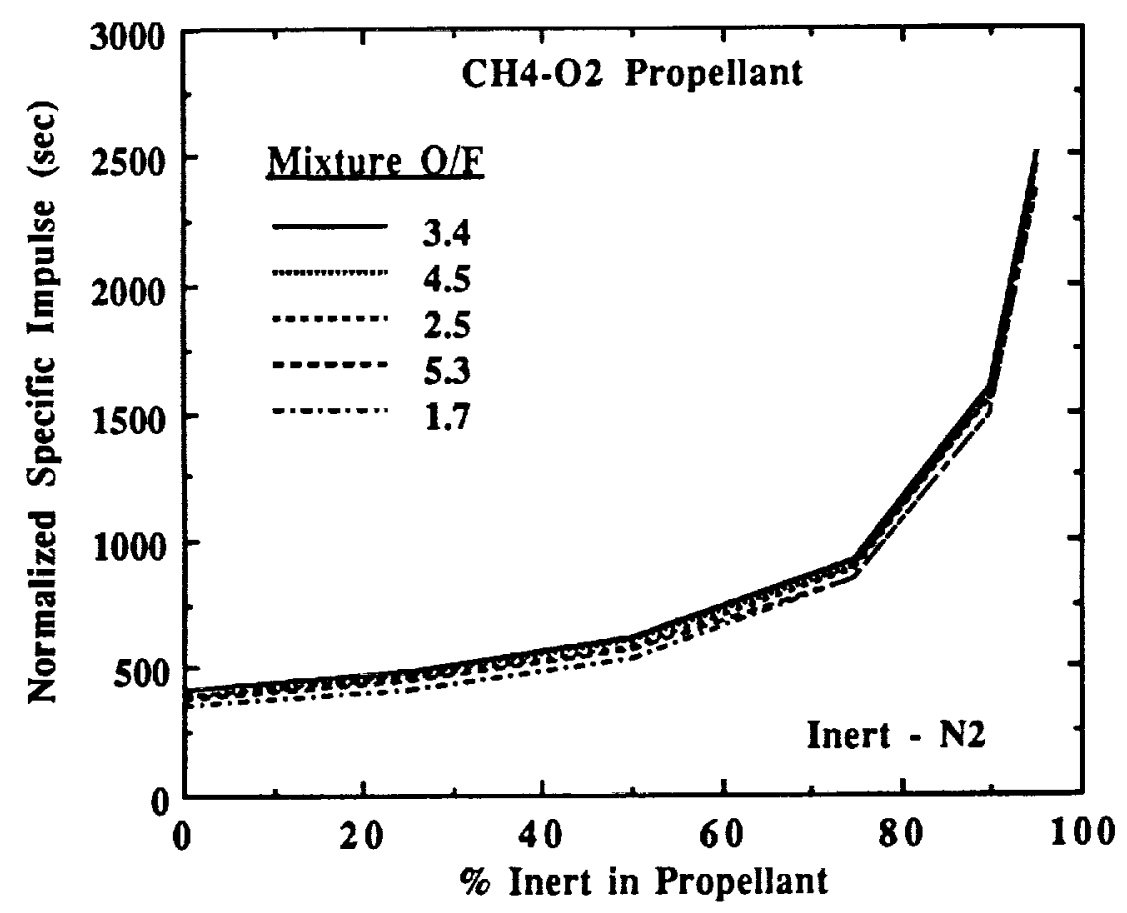

Figure 10. Isp $(F+O)$ [Specific impulse normalized to fuel and oxidizer flow], showing effect of addition of inert reaction mass to methane fueled engine while varying the mixture ratio

(Exit Area Ratio Constant at 200) 


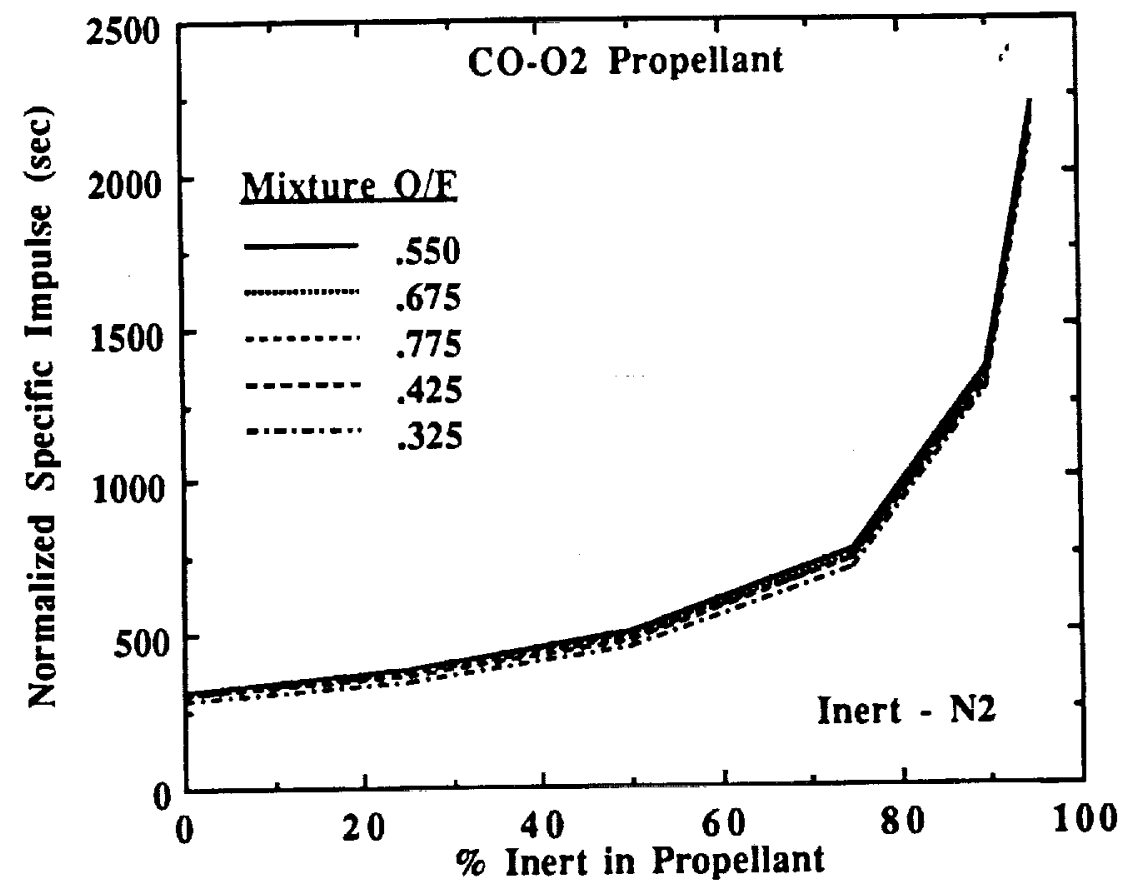

Figure 11. Isp $(F+O)$ [Specific impulse normalized to fuel and oxidizer flow], showing effect of addition of inert reaction mass to a carbon-monoxide fueled engine while varying the mixture ratio (Exit Area Ratio Constant at 200)

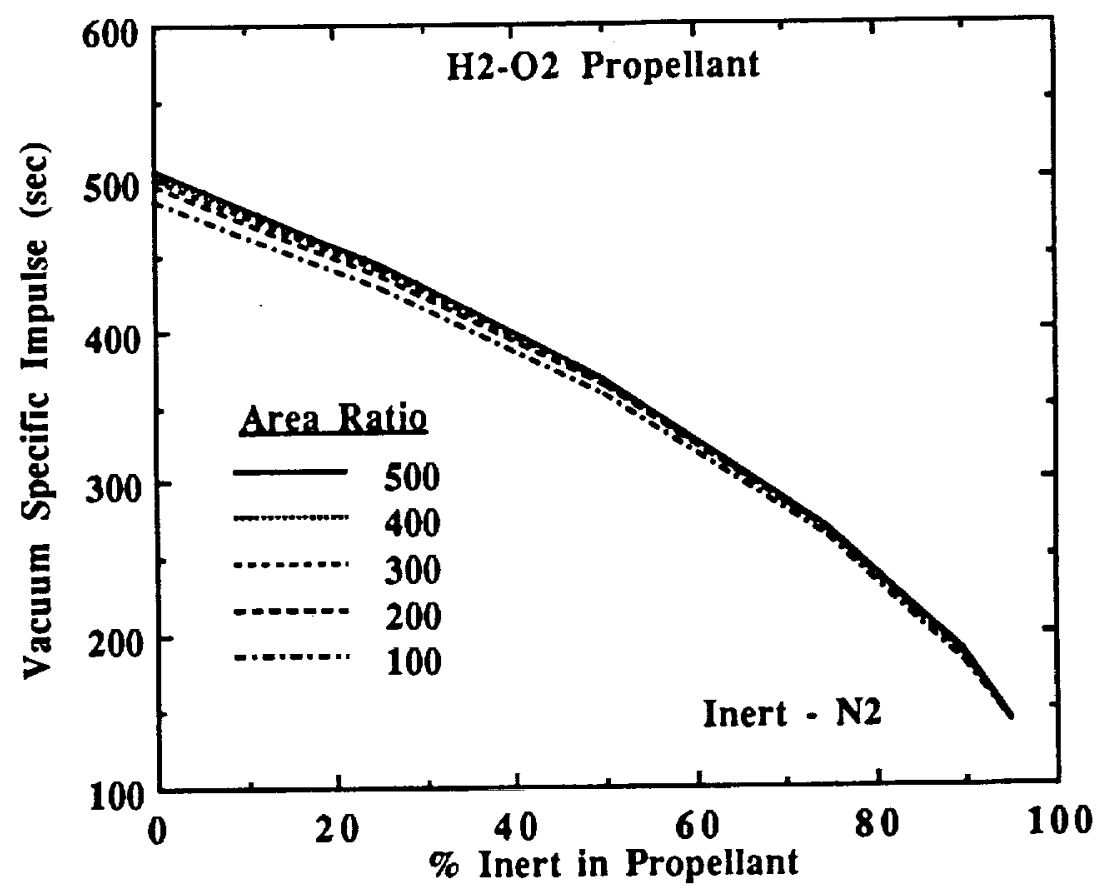

Figure 12. The Effects on propellant specific impulse due to the addition of nitrogen to a hydrogen-fueled engine While Varying the Exit Area Ratio

(Mixture Ratio - 6.0) 


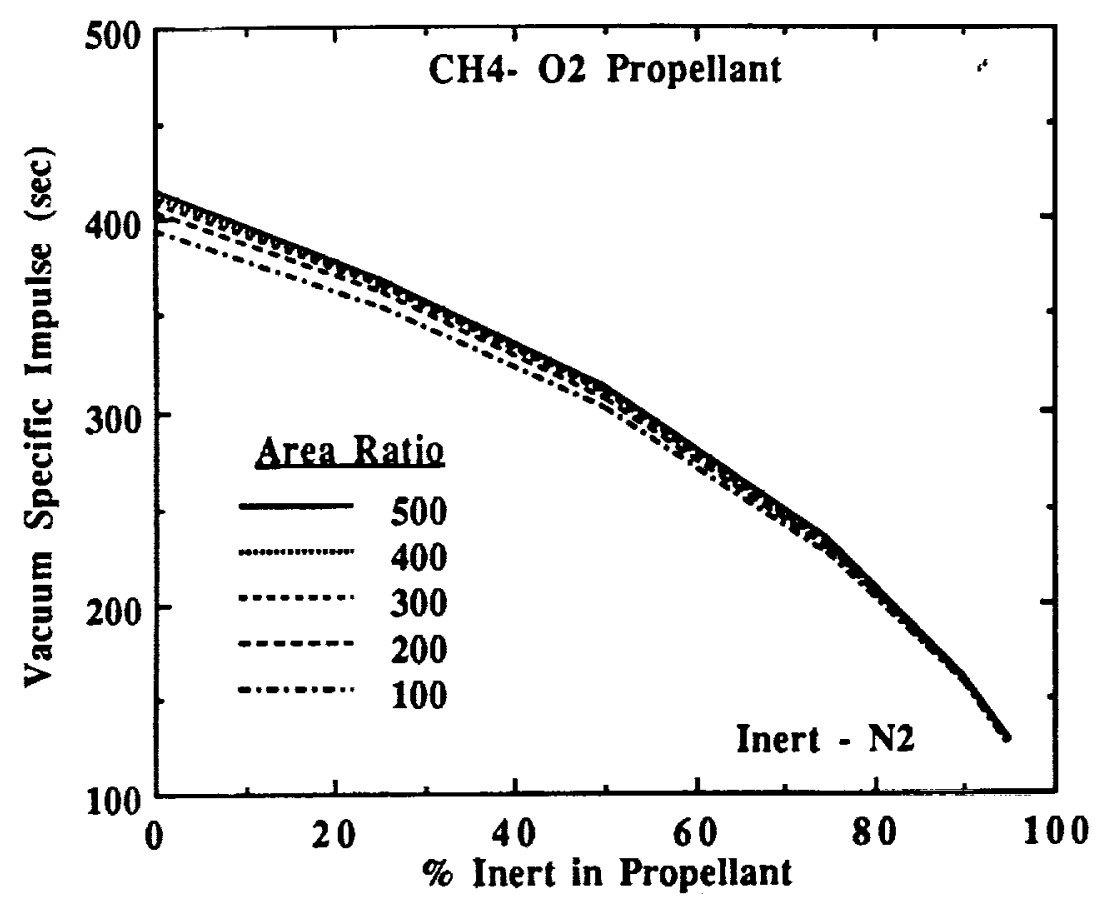

Figure 13. The Effects on propellant due to the Addition of motrpgem to a methane fueled engine While Varying the Exit Area Ratio

(Mixture Ratio - 3.4)

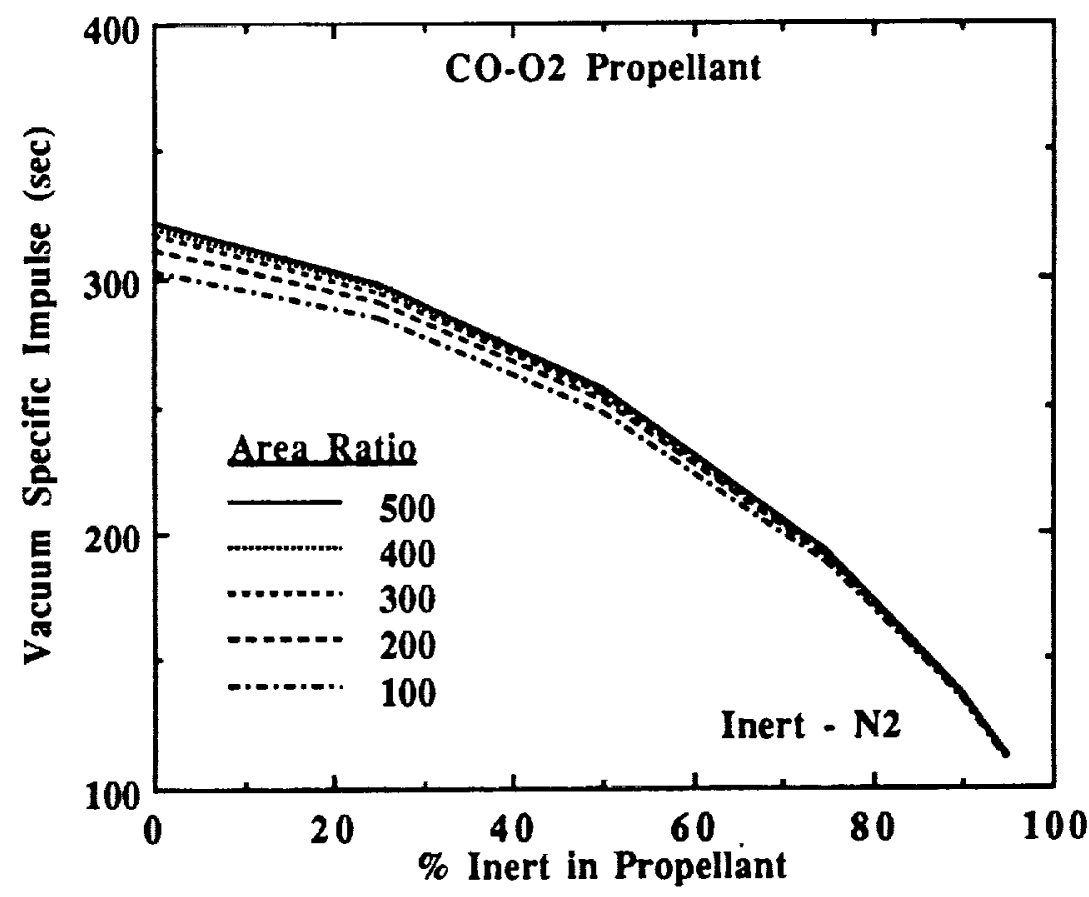

Figure 14 The Effects on $\mathrm{I}_{\mathrm{sp}}$ Due to the Addition of $\mathrm{N}_{2}$ to a carbon monoxide fueled engine While Varying the Exit Area Ratio

( Mixture Ratio - 0.55 ) 


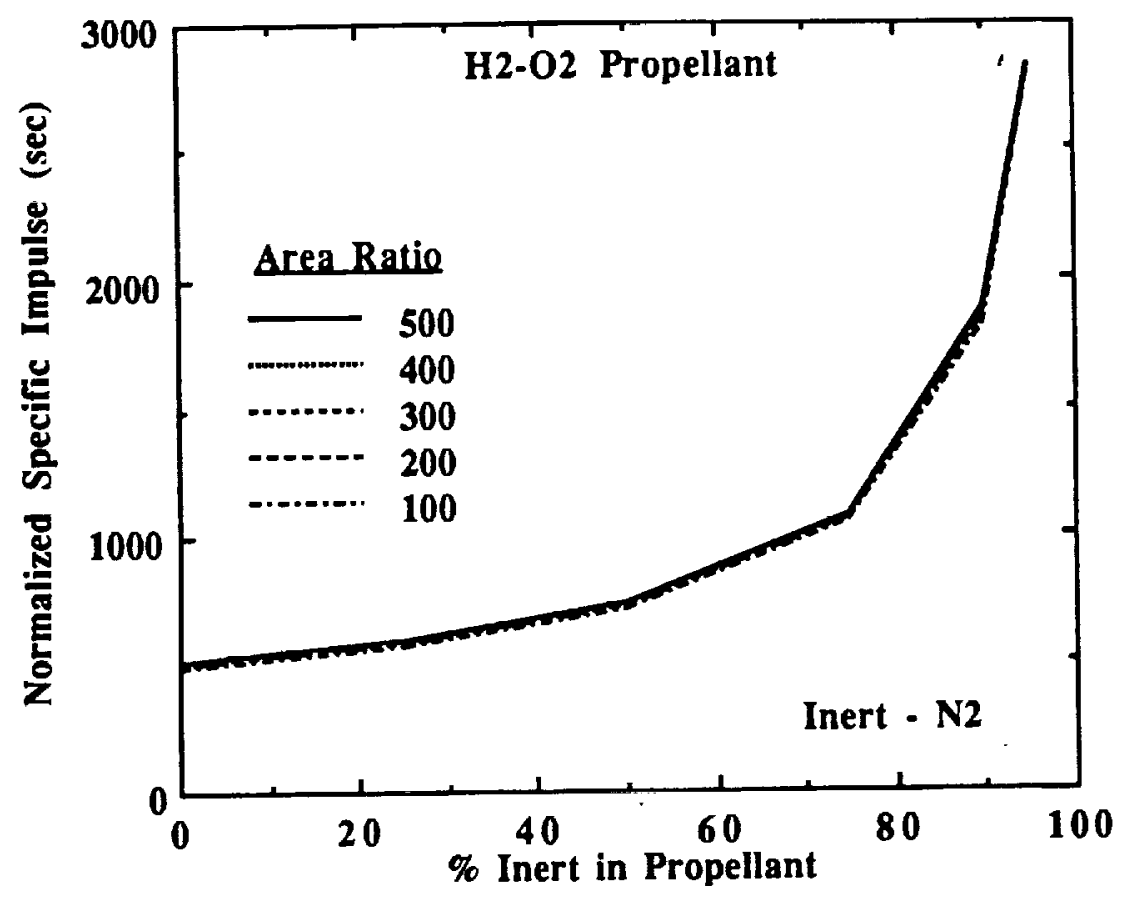

Figure 15. Isp(F+O) [Specific impulse normalized to fuel and oxidizer flow], showing effect of addition of inert reaction mass to a hydrogen fueled engine While Varying the Exit Area Ratio (Mixture Ratio - 6.0) 


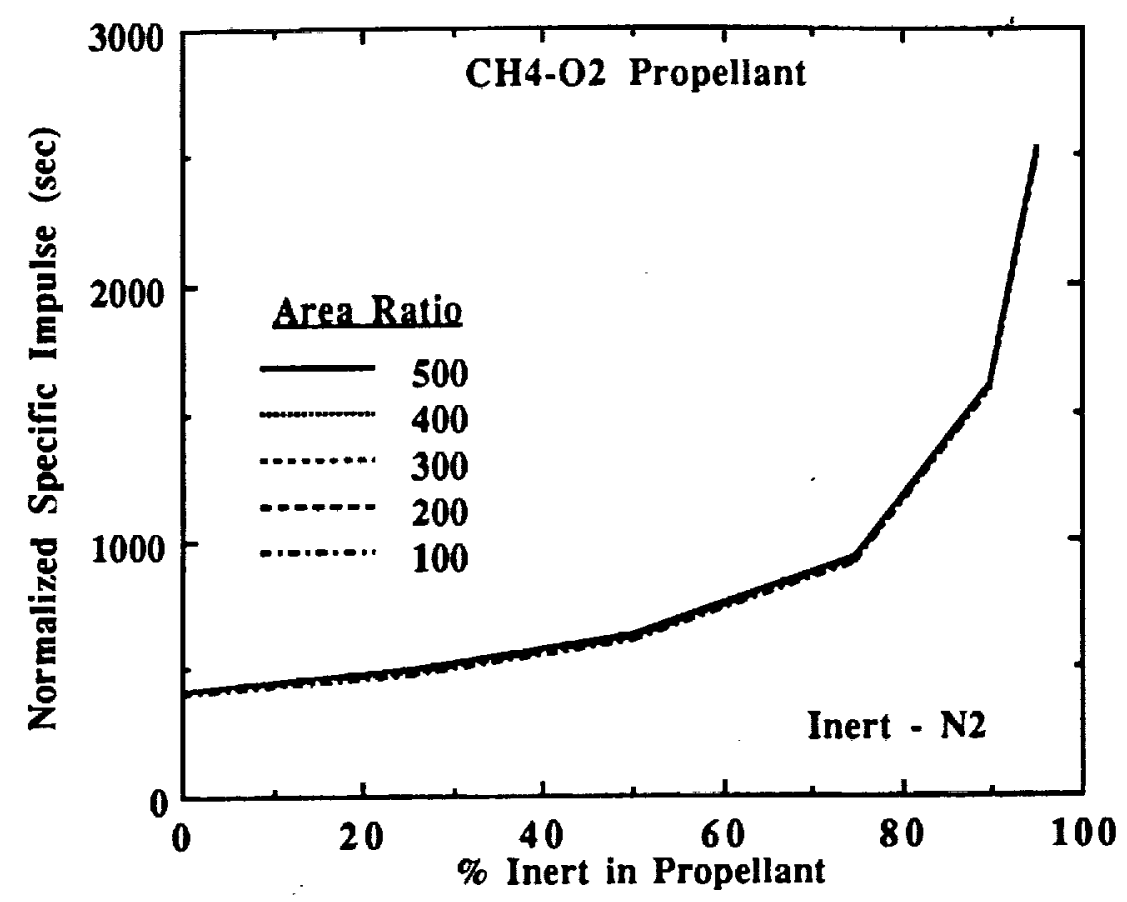

Figure 16. Isp $(F+O)$ [Specific impulse normalized to fuel and oxidizer flow], showing effect of addition of inert reaction mass to a methane fueled engine (Mixture Ratio - 3.4)

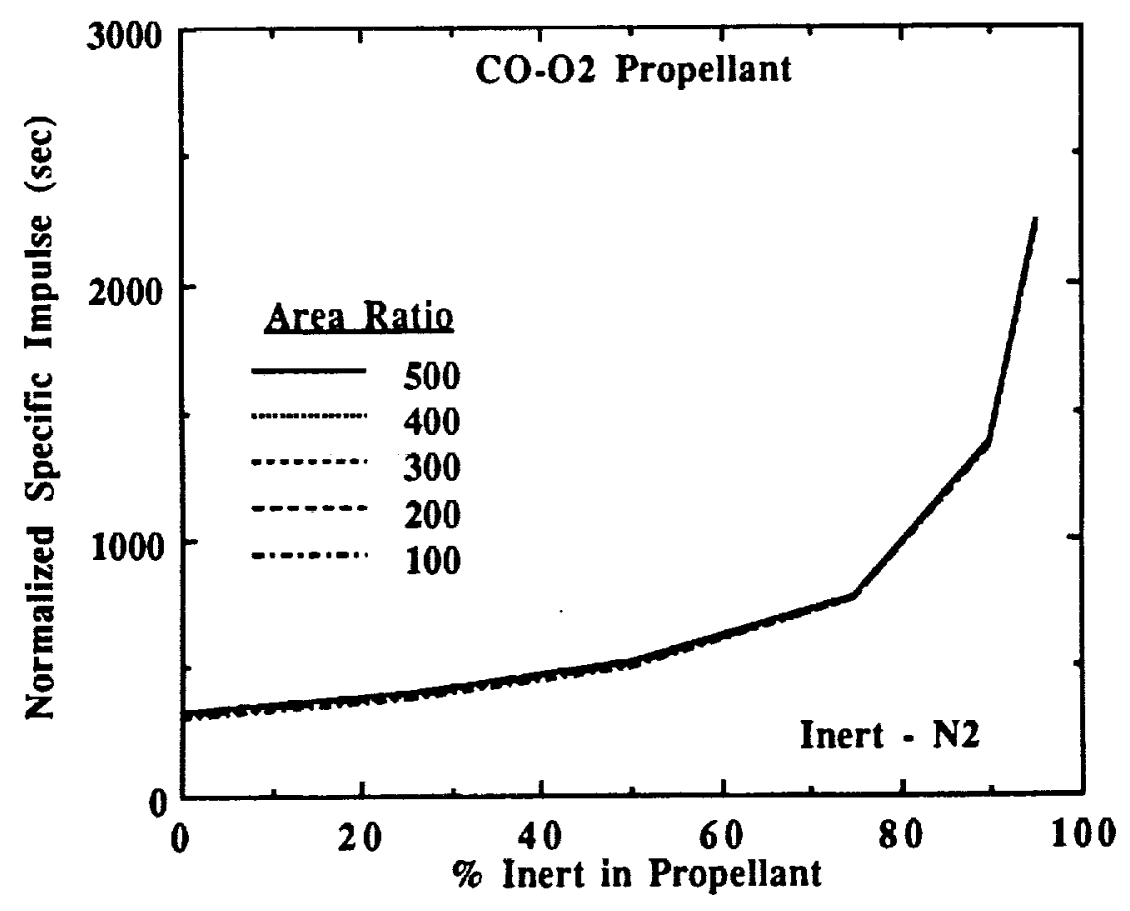

Figure 17. Isp $(F+O)$ [Specific impulse nomalized to fuel and oxidizer flow], showing effect of addition of inert reaction mass to a carbon-monoxide fueled engine While Varying the Exit Area Ratio (Mixture Ratio - 0.55 ) 


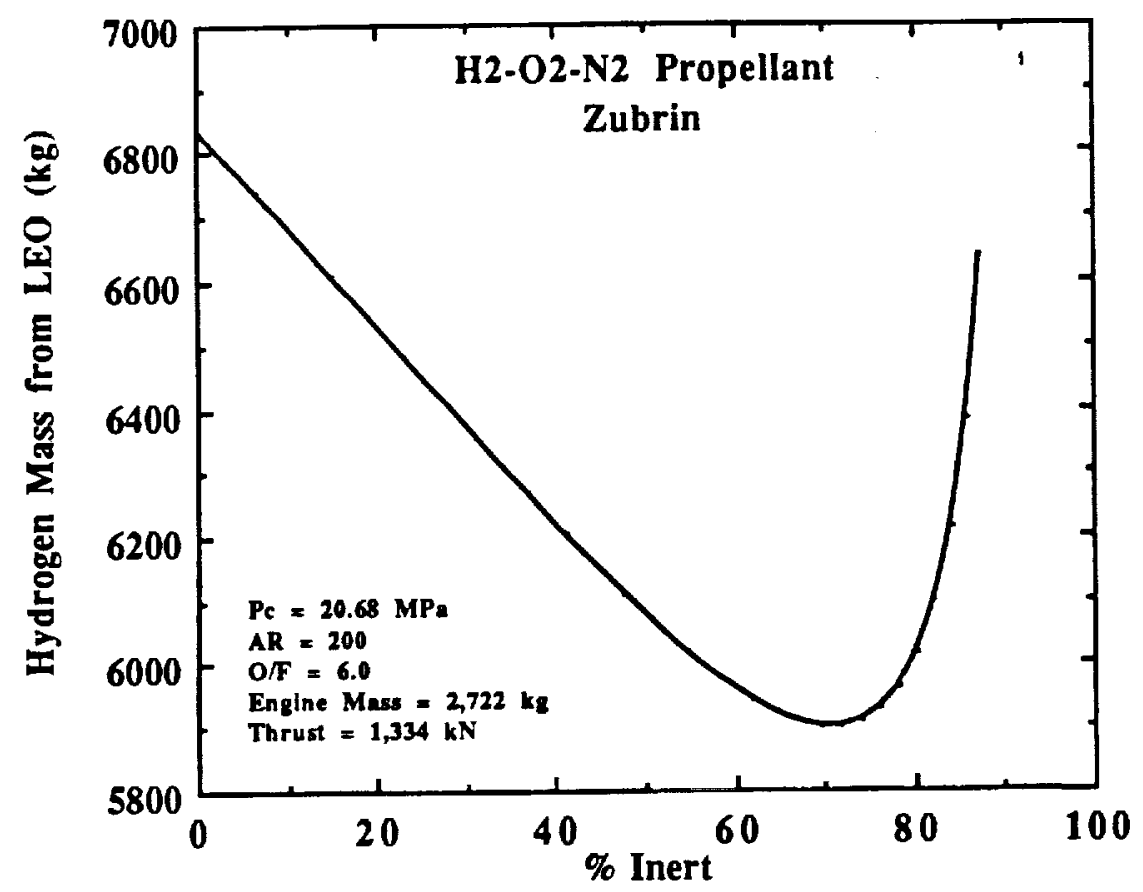

Figure 18. Hydrogen Mass required to Support the "Direct " return launch (two-stage launch from surface to Earth Injection) Using $\mathrm{H}_{2}-\mathrm{O}_{2}-\mathrm{N}_{2}$ Propellant Mixture

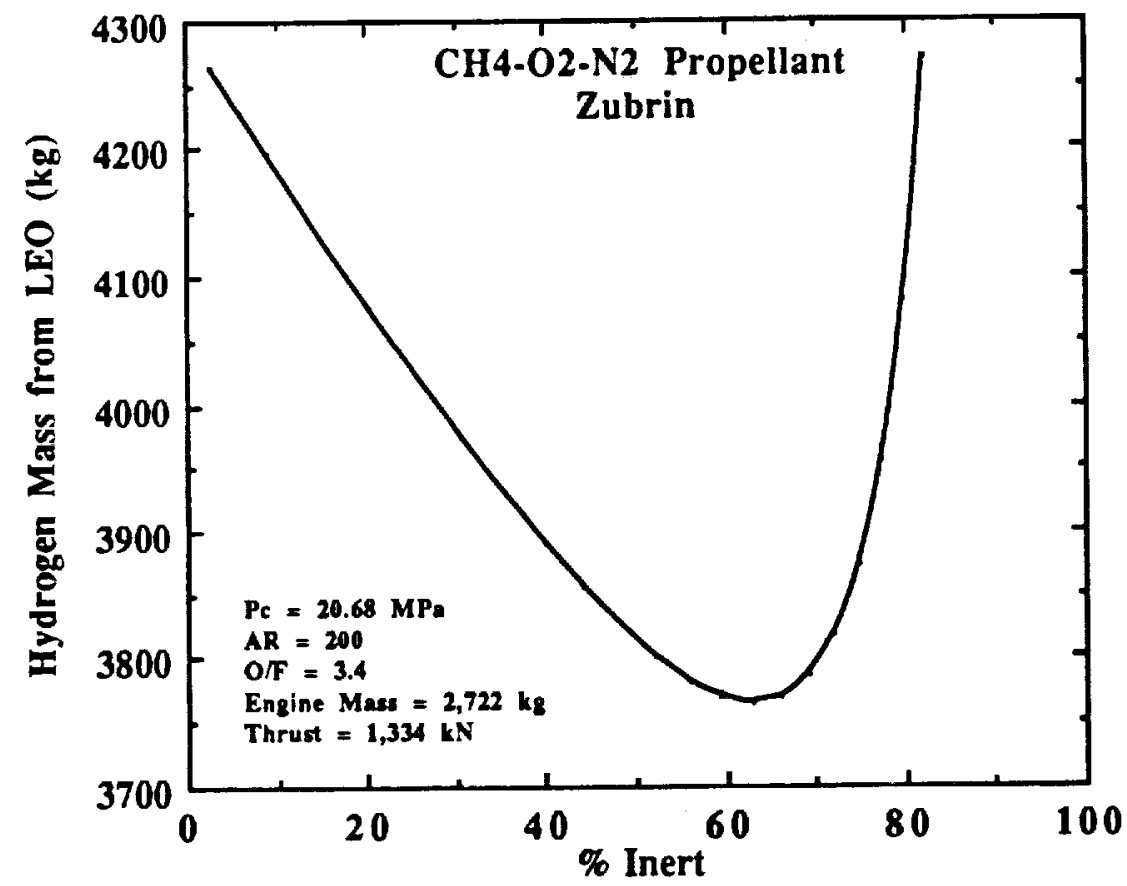

Figure 19. Hydrogen Mass required to Support the "Direct" retum launch (two-stage launch from surface to Earth Injection) Using $\mathrm{CH}_{4}-\mathrm{O}_{2}-\mathrm{N}_{2}$ Propellant Mixture 


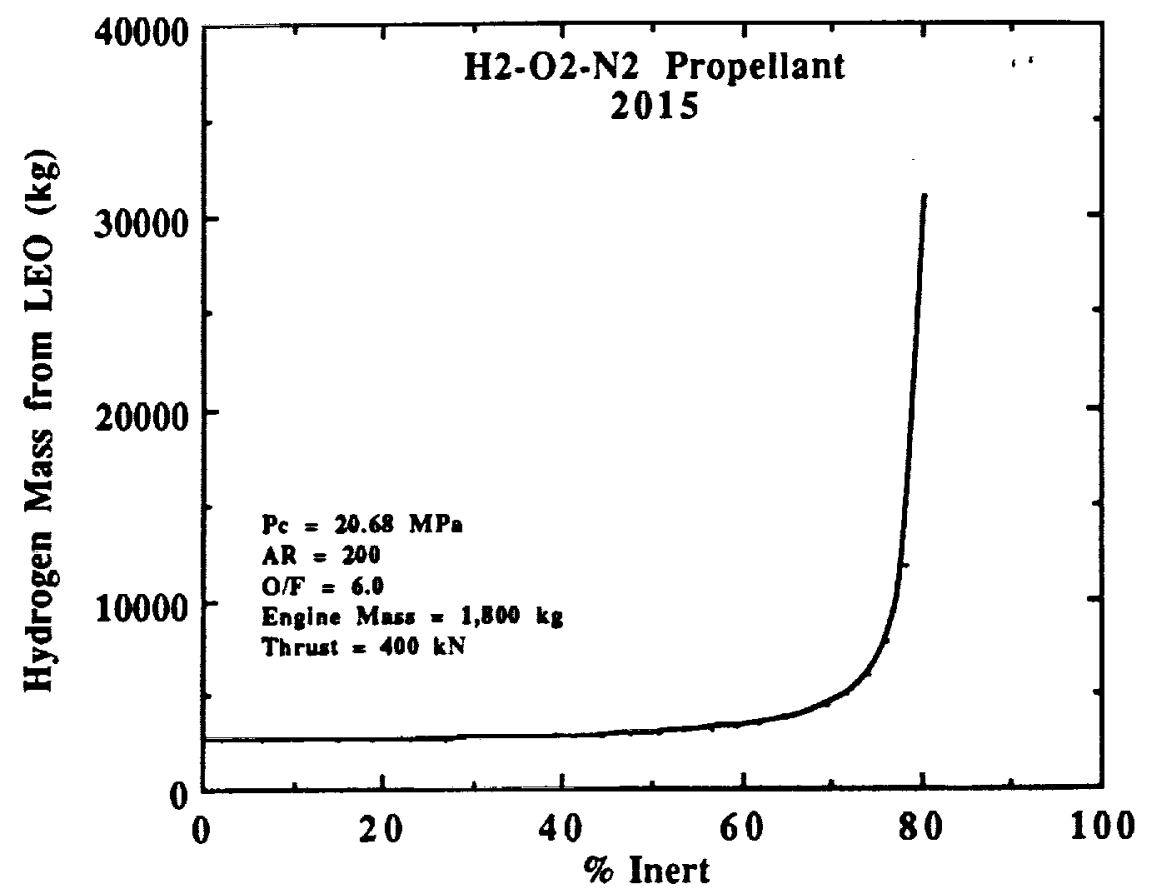

Figure 20. Hydrogen Mass required to Support the "2015 mission" return launch scenario (surface to mars orbit) with $\mathrm{H}_{2}-\mathrm{O}_{2}-\mathrm{N}_{2}$ Propellant Mixture

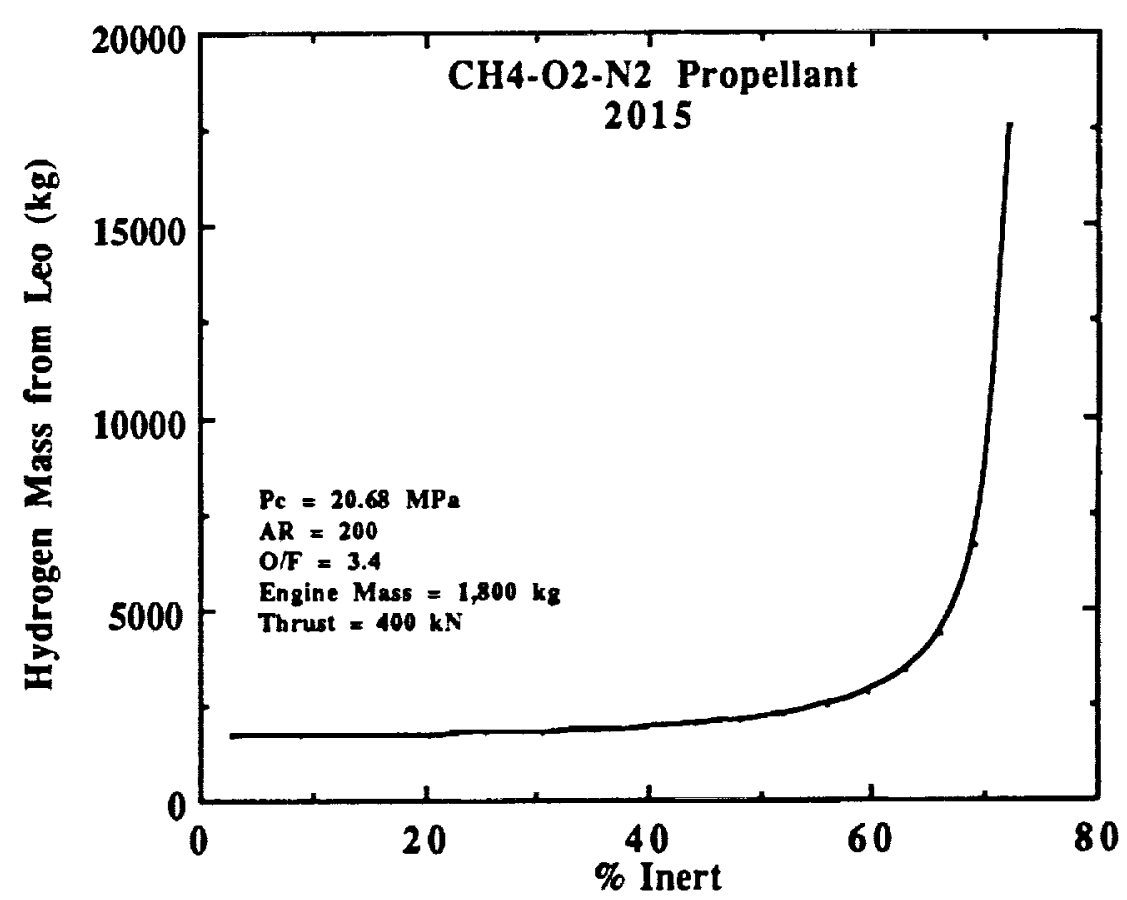

Figure 21. Hydrogen Mass required to Support the "2015 mission" return launch (surface to mars orbit) with $\mathrm{CH}_{4}-\mathrm{O}_{2}-\mathrm{N}_{2}$ Propellant Mixture 
Public reporting burden for this collection of inlormation is estimated to average 1 hour per response, including the time for reviewing instructions. searching existing data sources, gathering and maintaining the dala needed, and completing and reviewing the collection of intormation. Send comments regarding this burden estimate of any other aspect of this collection of information, Including suggestions for reducing this burden, to Washington Headquarers Services, Directorate lor ingertion Project (0704-0188), Washington, DC 20503.

Davis Highway, Suite 1204, Arlington, VA 22202-4302, and

1. AGENCY USE ONLY (Leave blank) 2. REPOAT DATE

September 1992

\section{REPOAT TYPE AND DATES COVERED}

Final Contractor Report
4. TTLE AND SUBTTLE

Effect of Inert Propellant Injection on

Mars Ascent Vehicle Performance

6. AUTHOR(S)

James E. Colvin and Geoffrey A. Landis

\section{PERFORMING ORGANIZATION NAME(S) AND ADDRESS(ES)}

Sverdrup Technology, Inc.

Lewis Research Center Group

2001 Aerospace Parkway

Brook Park, Ohio 44142

9. SPONSORING/MONITORING AGENCY NAMES(S) AND ADDRESS(ES)

National Aeronautics and Space Administration

Lewis Research Center

Cleveland, Ohio 44135-3191
5. FUNDING NUMBERS

WU-506-41-11
B. PERFORMING ORGANIZATION REPORT NUMBER

E-7312

10. SPONSORING/MONITORING AGENCY REPORT NUMBER

NASA CR-189238

AlAA-92-3447

\section{SUPPLEMENTARY NOTES}

Prepared for the 28th Joint Propulsion Conference and Exhibit cosponsored by the AIAA, SAE, ASME, and ASEE, Nashville, Tennessee, July 6 - 8 , 1992. James E. Colvin, University of Arizona Space Engineering Research Center, Tucson, Arizona 85712. Geoffrey A. Landis, Sverdrup Technology, Inc., Lewis Research Center Group, 2001 Aerospace Parkway, Brook Park, Ohio 44142. Responsible person, Gcoffrey A. Landis, (216) 433-2238.

12a. DISTRIBUTION/AVAILABILTTY STATEMENT

12b. DISTRIBUTION CODE

Unclassified - Unlimited

Subject Category

\section{ABSTRACT (Maximum 200 words)}

A Mars ascent vehicle is limited in performance by the propellant which can be brought from Earth. In some cases the vehicle performance can be improved by injecting inert gas into the engine, if the inert gas is available as an in-situ resource and does not have to be brought from Earth. Carbon dioxide, nitrogen, and argon are constituents of the Martian atmosphere which could be separated by compressing the atmosphere, without any chemical processing step. The effect of inert gas injection on rocket engine performance was analyzed with a numerical combustion code that calculated chemical equilibrium for engines of varying combustion chamber pressure, expansion ratio, oxidizer/fuel ratio, and inert injection fraction. Results of this analysis were applied to several candidate missions to determine how the required mass of return propellant needed in low Earth orbit could be decreased using inert propellant injection.

\begin{tabular}{l} 
14. SUBJECT TERMS \\
Rocket engines; Mars mis \\
\hline $\begin{array}{c}\text { 17. SECURITY CLASSIFICATION } \\
\text { OF REPORT } \\
\text { Unclassified }\end{array}$
\end{tabular}

18. SECUATY CLASSIFICATION
OF THIS PAGE
Unclassified
19. SECURITY CLASSIFICATION OF ABSTRACT Unclassified

